\title{
ABORIGINAL WOMEN SHARE THEIR STORIES IN AN OUTREACH DIABETES EDUCATION PROGRAM
}

\author{
A Thesis Submitted to the \\ College of Graduate Studies and Research \\ In Partial Fulfillment of the Requirements \\ for the Degree of Master of Science \\ in the Department of Community Health \& Epidemiology. \\ University of Saskatchewan \\ Saskatoon, Saskatchewan
}

By

Mary Patricia Dressler

Winter 2003

(C) Copyright Mary Patricia Dressler, 2003. All rights reserved. 


\section{PERMISSION TO USE}

In presenting this thesis in partial fulfillment of the requirements for a Masters degree from the University of Saskatchewan, I agree that the Libraries of this University may make it freely available for inspection. I further agree that permission for copying of this thesis in any manner, in whole or in part, for scholarly purposes may be granted by the professor or professors who supervised my thesis work or, in their absence, by the Head of the Department or the Dean of the College of Medicine. It is understood that any copying or publication or use of this thesis or parts thereof for financial gain shall not be allowed without my written permission. It is also understood that due recognition shall be given to me and to the University of Saskatchewan in any scholarly use which may be made of any material in my thesis.

Requests for permission to copy or to make other use of material in this thesis in whole or in part should be addressed to:

Head of the Department of Community Health and Epidemiology

College of Medicine

University of Saskatchewan

Saskatoon, Saskatchewan S7N 5E5 


\begin{abstract}
Compared to other Canadians, Aboriginal people suffer disproportionately from Type 2 diabetes and its complications. In an attempt to fill gaps in services for Aboriginal people to support better management of diabetes and to prevent further complications, the West Side Community Clinic launched a monthly outreach diabetes education program using an informal hands-on approach to learning about meal planning and other forms of diabetes management. The purpose of this qualitative study was to determine the impact that the program has had on the participants' health and well-being through the stories they shared in a group or individual interview. Out of the core group of 30 women, most of them Aboriginal, eleven participated in the group interview and five women participated in individual interviews.

Findings reveal that the program's impact on participants' health and well-being is embedded within the context of their lives. Diabetes is managed within multiple life realities in an individual, a familial and a community context. The women report learning management skills and sharing support among participants and staff of Diabetes Morning; and altered health status such as regulated blood glucose levels and weight loss. Opportunities for change include more programming like Diabetes Morning, more often, more information, access to low-cost diabetes-friendly foods, communication with health care practitioners, and integrating knowledge on a day-to-day basis. Domains for outcome indicators and contextual indicators are suggested for the program.
\end{abstract}




\section{ACKNOWLEDGEMENTS}

I owe my deepest gratitude to the many people who contributed to the completion of my thesis:

To the women in the Diabetes Morning group for sharing their stories.

To Carol Armstrong-Monohan, Marilee Bailey, Nola Kornder, and West Side Community Clinic for inviting me to experience this opportunity.

To my committee members for their support throughout the research process: Joan Feather (Supervisor); Bruce Reeder (Chair); Sylvia Abonyi; Elder Laura Wasacase; and Carol Armstrong-Monohan. I would like to thank Kathryn Green and Dr. Tan for their contributions to the process in the early stages. Also, to Allan Ryan who served as the external examiner for my defense.

To the Department of Community Health \& Epidemiology for financial support and to my teachers: Murray Dickson, Anne Leis, Nazeem Muhajarine, Bruce Reeder, Senthil Selvan, Dr. Tan and my classmates. Also, to Fran MacKay for her administrative guidance and support.

To the Community-University Institute for Social Research (CUISR) for financial support.

To Vivian Ramsden and the Department of Family Medicine for their support and the opportunity to apply my skills.

To Clarence Clottey for his guidance, encouragement and unwavering belief in my ability to achieve whatever I set my mind to accomplish.

To many relatives and friends who encouraged me throughout the years.

To my family: My mom, Pauline Stang for her prayers and support as I maintained focus to complete what I had begun; and my brothers: Egbert Stang for his constant reminders through the years of my potential; and Leon Stang and Dale Wilson for always being there. In particular: Thank you to my younger and only sister, Anita Wilson who has become a precious friend since she entered my life in my eighth year, and whose wisdom often surpasses mine; And, to my children, Diane, Donny and Darlene Fisher, my cheerleading section. They are growing into fine young women and a fine young man. Their resilient souls have weathered the storms of change. I am so proud of them. Thank you for being in my life.

"One thing I know to be certain in this world and that one thing is change... what is to be has already begun." -MP Dressler 


\section{DEDICATION}

In dedication to my children, Diane, Donny and Darlene, who continue to be the impetus behind my decisions that broaden our horizons.

I love you for eternity! 
TABLE OF CONTENTS

PERMISSION TO USE

ABSTRACT

ACKNOWLEDGEMENTS iii

DEDICATION

TABLE OF CONTENTS $\quad v$

LIST OF TABLES viii

LIST OF FIGURES ix

CHAPTER 1. INTRODUCTION 1

1.1 The Purpose of this Study 1

1.2 An Opportunity for Change 2

1.3 The Present Study 6

1.3.1 Determine the impact that Diabetes Morning has had on the participants' health and well-being 7

1.3.2 Suggest possible outcome indicators based on the stories of the participants

$\begin{array}{lll}1.4 & \text { An Overview of the Chapters } & 7\end{array}$

CHAPTER 2. THE PROGRAM: DIABETES MORNING 9

$\begin{array}{lll}2.1 & \text { Introduction } & 9\end{array}$

2.2 Origin 9

2.3 The Performance Improvement Conceptual Model 10

$\begin{array}{lll}2.3 .1 & \text { Program Objectives } & 12\end{array}$

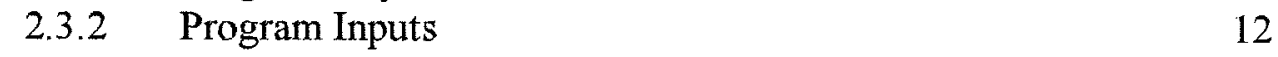

2.3.3 Program Activities 13

2.3.4 Program Outputs 14

2.3.5 Program Outcomes 14

$\begin{array}{lll}2.4 \text { Program Records } & 15\end{array}$

2.4.1 Records about Individuals 16

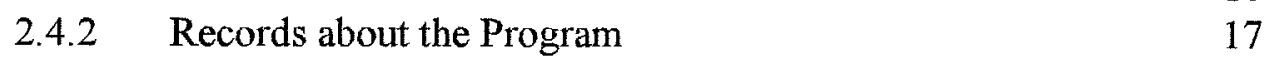

2.5 Diabetes Morning Program Focus Group Results 17 
3.1 Introduction 21

3.2 Qualitative Methods of Enquiry 21

3.3 Rigor in Qualitative Research 22

3.4 The Process 25

3.4.1 The Presence of the Researcher 25

$\begin{array}{ll}3.4 .2 & \text { Literature Review Process } \\ 3.4 .3 & 27\end{array}$

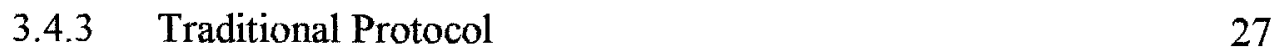

3.4.4 Point of Entry $\quad 28$

$\begin{array}{ll}3.4 .5 & \text { Participants } \\ 3.4 .6 & 29\end{array}$

3.4.6 Funding and other Support for the Research 29

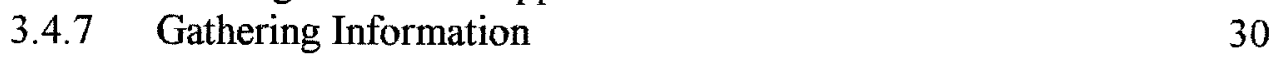

3.4.8 My Reflections $\quad 32$

$\begin{array}{lll}3.4 .9 \text { Consent } & 32\end{array}$

CHAPTER 4: FINDINGS

4.1 Introduction $\quad 34$

4.2 Participants' Attendance 35

4.3 The Context of their Lives 36

$\begin{array}{ll}4.3 .1 \text { Diagnosis } & 36\end{array}$

$\begin{array}{lll}4.3 .2 & \text { Treatment } & 38\end{array}$

4.3.3 Self-management 40

4.3.4 Conditions of life related to the experience of diabetes 42

4.3.5 The impact of relationships on the experience of diabetes

4.4 The Impact of Diabetes Morning 44

4.4.1 Cooking 46

4.4.2 Information and support sharing among participants 46

4.4.3 Information and support sharing with staff 48

CHAPTER 5: DISCUSSION AND CONCLUSION 51

5.1 Introduction 51

5.2 The Impact of Diabetes Morning on the Women's Health and Well-being

5.2.1. Objectives of the Program 52

5.2.2. Projected Outcomes, 1999 Diabetes Morning focus group results and positive impacts of the program as possible outcome indicators $\quad 52$

5.3 Living with Diabetes $\quad 62$

5.3.1 Domains for Contextual Indicators 68

$\begin{array}{lll}5.4 & \text { Implications of the Findings } & 73\end{array}$

5.5 Strengths and Limitations of the Study 76 
$\begin{array}{lll}5.6 & \text { Further Research } & 77\end{array}$

5.7 Conclusion 78

$\begin{array}{ll}\text { REFERENCES } & 79\end{array}$

$\begin{array}{ll}\text { BIBLIOGRAPHY } & 86\end{array}$

APPENDIX A: Diabetes Morning General and Medical Information 93

APPENDIX B: Diabetes Morning Program Debriefing Notes and Problem

$\begin{array}{ll}\text { Management } & 95\end{array}$

APPENDIX C: Group Interview Guide 97

APPENDIX D: Individual Interview Guide 99

APPENDIX E: Consent Form: Group Interview 100

APPENDIX F: Consent Form: Individual Interview 103

APPENDIX G: Debriefing Form 106

APPENDIX H: Transcript Release Form 107 


\section{LIST OF TABLES}

Table 1: Structure of Diabetes Morning based on the "Performance Improvement Model" (adapted from Diabetes Morning program documentation)

Table 2: Focus group $(\mathrm{N}=14)$ results based on the five most important statements chosen by the participants and rated and associated with projected outcomes by program staff (adapted from program documentation)

Table 3: Explanation of Criteria and Strategies for Evaluating Rigor in Qualitative Research (adapted from Lincoln \& Guba 1985; Leininger, 1994)

Table 5: Diabetes Morning projected outcomes, 1999 Focus group results of participant-identified expected outcomes and health needs, and positive impacts of Diabetes Morning as domains for outcomes indicators

Table 6: Possible contextual indicators for living with diabetes 


\section{LIST OF FIGURES}

Figure 1: United Way's Program Outcome Model ${ }^{21}$ 


\section{CHAPTER ONE}

\section{INTRODUCTION}

\subsection{The Purpose of this Study}

The purpose of this study was to: determine the impact that Diabetes Morning, an outreach diabetes education program, had on the participants' health and well-being based on their experiences; and to suggest possible outcome indicators based on their stories. Health is referred to in its broadest sense as "a state of complete physical, mental, and social well-being and not merely the absence of disease or infirmity," which is the World Health Organization's (WHO) 1948 definition. The WHO has since reformulated this comprehensive definition. Health is:

"...the extent to which an individual or group is able on the one hand to realize aspirations and satisfy needs, and, on the other hand, to change and cope with the environment. Health is therefore seen as a resource for everyday life, not the objective of living; it is a positive concept emphasizing social and personal resources as well as physical capacities."(p. 1)

Considering this definition of health, well-being is referred to as being in a state of health. The impact of Diabetes Morning is determined by the benefits participants experienced to their health and well-being as expressed in the interviews. Possible outcome indicators are drawn from these expressed benefits. Reference is also made to gaps in service and unmet needs shared by the study participants. 


\subsection{An Opportunity for Change}

Diabetes is the seventh leading cause of death in Canada. Health Canada reported 25,000 potential years of life lost in 1996 due to this devastating disease. ${ }^{2}$ Among Aboriginal people in Canada, Type 2 diabetes $^{*}$ is one of the most commonly reported chronic illness. ${ }^{3}$ WHO has included diabetes among the diseases where there has been an international agreement on definition. ${ }^{4}$ Diabetes mellitus is a metabolic disorder of multiple etiologies. Chronic hyperglycemia is characteristic of this disease.

Disturbances in carbohydrate, fat and protein metabolism result from defects in insulin secretion and/or insulin action. Type 2 diabetes is the most common form of diabetes resulting from defects in insulin secretion or insulin resistance. ${ }^{5}$ Herein, diabetes is defined as Type 2 diabetes.

Compared to other Canadians, Aboriginal people suffer disproportionately from Type 2 diabetes and its complications. Type 2 diabetes prevalence rates in Canada are three times higher among Aboriginal men and five times higher among Aboriginal women than in the non-Aboriginal population. ${ }^{6,7}$ Based on reported cases, Aboriginal people who reside in Saskatchewan, Manitoba and Ontario face the highest risk of diabetes with Aboriginal residents of British Columbia facing the lowest risk. ${ }^{2}$ In Saskatchewan, the epidemic is compounded by the fact that the proportion of the Aboriginal population is four times higher in Saskatchewan than in Canada as a whole: $11 \%$ versus $2.8 \%{ }^{8}$

Diabetes prevalence rates increase with age: Aboriginal people over 65 years of age face a $22.8 \%$ risk of being diagnosed with diabetes compared with a $10 \%$ risk faced

\footnotetext{
The classification of diabetes has been revised over the years. The term Type 2 diabetes is presently used. ${ }^{3}$ In this study, the term 'diabetes' refers to Type 2 diabetes.
} 
by Aboriginal people 15 years and older. ${ }^{2}$ Incidence of diabetes reported in a 1998 Saskatchewan study revealed more than $50 \%$ of the First Nations participants over the age of 60 met the diagnostic criteria for diabetes. ${ }^{3}$ In addition, more and more Aboriginal children are being diagnosed with Type 2 diabetes, a disease virtually unheard of in children in the past., ${ }^{9,10}$ Now, Aboriginal people as young as 15 years of age are being diagnosed with Type 2 diabetes. ${ }^{11}$

Canadian Aboriginal people with Type 2 diabetes encounter more serious longterm complications from the disease than do other Canadians. ${ }^{9}$ Diabetes is the leading cause of blindness, kidney failure, and limb amputations and a major cause of heart disease and stroke. In addition, the economic burden caused by diabetes and its complications includes increased health care utilization, disability, work loss, and premature death. ${ }^{2}$ In a 1996-97 report from Saskatchewan's Women's Secretariat, Saskatchewan First Nations women were found to be 24 times more likely to be hospitalized due to diabetes than other women in the province. ${ }^{12}$

The good news is that Type 2 diabetes and its complications are preventable and can be managed, in part, by a healthy lifestyle, which includes a healthy diet and regular exercise, ${ }^{13}$ and monitoring blood sugar and blood pressure levels. ${ }^{2}$ Aboriginal communities across Canada are introducing programs that promote healthy living. ${ }^{10,14,15}$ Walking trails, cooking groups, Grade Three and Four curriculum changes, modification of school cafeteria menus, and the removal of vending machines from schools all fall within the range of interventions used to improve lifestyle practices in communities. In 1999, Saskatchewan Health introduced a new health initiative, "Population Health Promotion Demonstration Projects for the Primary Prevention of Diabetes."16 Districts or service areas were invited to propose collaborative, intersectorial approaches toward addressing diabetes. Health districts, Aboriginal groups, community groups and other 
sectors were encouraged to work collaboratively at the community level to address the growing issue of diabetes through the broad range of health determinants from a population health perspective. This perspective involves investigating "why some people are healthier than others."1 The broad range of determinants include income and social status, social support networks, education, employment and working conditions, physical environment, biology and genetic endowment, personal health practices and coping skills, healthy child development, and health services. ${ }^{17}$

For the most part, Population Health Promotion Demonstration Projects are geared toward primary prevention of diabetes with the goal of preventing disease and reducing incidence and prevalence of the disease. ${ }^{17}$ Given the large number of people already living with diabetes, primary prevention strategies are only a piece, albeit a significant one, to addressing diabetes. As a chronic disease, diabetes requires clinical intervention (ie: monitoring blood sugar levels and blood pressure) as well as primary prevention strategies to manage the disease and prevent further complications.

Young presents five types/levels of population health interventions ${ }^{\dagger}$ in relation to the natural history of disease and the impact of these interventions on five measures of health status. The five population health interventions are: primary prevention; early detection; clinical treatment; rehabilitation; and palliation. The natural history of disease includes: exposure; latent phase; acute phase; chronic phase leading to recovery or complications; and complications leading to recovery or death. The five measures of health status are: incidence; prevalence; mortality; case-fatality; and quality of life. ${ }^{18}$ Building on primary prevention and early detection strategies, clinical treatment is an appropriate population health intervention during the acute and chronic phase of disease

\footnotetext{
${ }^{\dagger}$ Health intervention is defined as " an action which reduces the frequency, duration, or severity of disease and promotes the health and well-being of the individual, family or community." 18
} 
and when complications are present. Impacts of clinical treatment on measures of health status include decreased mortality and case-fatality, and improved quality of life for the target population.

Whiting, Waldram, Habbick, and Kornder's 1998 study called "A Diabetes education program for urban dwelling Aboriginal people, ${ }^{\prime 19}$ was initiated with an overall goal to improve the health of Aboriginal people who are already burdened with diabetes. A specific goal of this study was to involve the Saskatoon Aboriginal community and community agencies in the program development and evaluation process in order to improve the potential for continued intervention after the research project was complete. They found that Aboriginal people were not accessing the existing diabetes education programs such as the Diabetes Education Centre (DEC) located in the Royal University Hospital and St. Paul's Hospital. They found that the existing diabetes education programs addressed a need for basic information and skills to manage diabetes but did not address the complications caused by low income and relocation such as isolation, the inability to purchase appropriate foods, transportation needs, and the need for a trusting environment. These findings coincide with the First Nations and Inuit Regional Health Surveys, which identified several gaps and challenges related to existing services. They found that gaps in diabetes education/awareness programs as well as accessibility to these services needed to be addressed. ${ }^{3}$ Challenges identified in this survey include language and cultural barriers, lack of understanding of the health and social conditions facing Aboriginal people, diabetes education, geography, and food security.

Consequently, a partnership was formed between the Diabetes Education Centre and the Saskatoon Community Clinic to pilot an outreach diabetes education program from the Saskatoon Community Clinic's west side location. The West Side Community Clinic is located within the core communities where many Aboriginal people and people 
on low income reside. The program, Diabetes Morning, is a food resource program where people come together to cook. Information and support relevant to diabetes management, including blood sugar and blood pressure monitoring, care for eyes and feet as well as meal planning is provided. Transportation costs and childcare costs are also subsidized for those who require the financial support.

Diabetes Morning has been successful in terms of attracting Aboriginal women with Type 2 diabetes; 12 to 14 women, mostly Aboriginal, attended the group on a monthly basis. Men occasionally attended but they were less likely to continue. In order to continue to improve services to meet the needs of Aboriginal people with Type 2 diabetes, more information was needed about effective intervention for managing diabetes: what works and how. The staff of Diabetes Morning was interested in evaluating the program and saw the first step as understanding how the program affected the women's health and well-being. This information could be used to develop possible outcome indicators for use in program planning and evaluation. Therefore, staff entered into discussion with my committee and me about this study design to meet my needs for my thesis and the program's needs.

\subsection{The Present Study}

The purpose of this study is to:

- Determine the impact that Diabetes Morning has had on the participants' health and well-being based on their experiences, and

- Suggest possible outcome indicators based on the stories of the participants. 
1.3.1 Determine the impact that Diabetes Morning has had on the participants ${ }^{2}$ health and well-being

Qualitative methods were used in this study as a means of capturing the multiple realities of the participants. This study was designed to identify the impact that Diabetes Morning had on the participants' health and well-being through the stories they shared in a group interview and/or an individual interview. Stories were obtained using openended questions. The analysis involved abstracting themes and sub-themes from the participants' interview transcripts. Attendance rates are also reported. These findings are presented in Chapter Four organized under three categories: participants' attendance, the context of their lives, and the impact of Diabetes Morning.

\subsubsection{Suggest possible outcome indicators based on the stories of the participants}

In Chapter Five, the findings from Chapter Four are discussed in relation to the Diabetes Morning conceptual model and the results of the 1999 Diabetes Morning focus group conducted by the staff when the program first started. Impacts of Diabetes Morning on the participants' health and well-being are abstracted from the findings and suggested as domains in which outcome indicators could be developed.

\subsection{An Overview of the Chapters}

In Chapter One, background information is presented about diabetes among Aboriginal people, how Diabetes Morning began, and the purpose of this study. Chapter Two is an overview of the Diabetes Morning program, its origin, a description of its 
conceptual model and program records, as well as the results of a focus group facilitated by staff with the participants in the early stages of the program. Chapter Three describes the qualitative methods and the procedures that were followed. Chapter Four is a presentation of the findings including attendance rates, the context of the lives of the participants and the impact of the program. Chapter Five is a discussion of these findings with concluding comments. Discussion includes the impact of the program and domains for outcome indicators for the program; living with diabetes; and domains for contextual indicators. Implications for the program and strengths and limitations of the study are discussed. Further research is suggested. 


\section{CHAPTER 2}

\section{THE DIABETES MORNING PROGRAM}

\subsection{Introduction}

The following section describes the Diabetes Morning program; how it began, its conceptual framework, program records and the results of a focus group conducted by program staff members. This information was obtained from program documentation and in consultation with program staff.

\subsection{Origin}

Diabetes Morning arose from the Diabetes Education Center's (DEC) desire to increase community involvement and improve services for managing diabetes among Aboriginal people residing in Saskatoon. While Diabetes Morning was originally intended for Aboriginal people, low-income men and women of all ethnic backgrounds were invited to attend. The core group of participants of the Diabetes Morning program continues to be comprised primarily of Aboriginal women.

Diabetes Morning employs a hands-on experiential approach as a method of learning how to manage diabetes. The program provides an opportunity to socialize with others within a familiar environment. Advocacy is also provided for participants who face financial constraints and require an increased dietary allowance from the Department of Social Services to purchase necessary foods and a blood glucose meter for regular blood testing. 
Diabetes Morning has met monthly at West Side Community Clinic since the fall of 1999. It is primarily a food resource program that provides information and support relevant to diabetes management including blood testing and blood pressure checks, and care for eyes and feet, as well as meal planning. Low cost meals are chosen by the clinic's nutritionist in consultation with the participants and prepared by these women on a monthly basis. One meal is shared as a group and another is prepared to take home. The rationale for using a hands-on approach is that participants can learn to make wise food choices within their financial constraints and to control portion size by learning what an appropriate serving size looks like.

\subsection{The Performance Improvement Conceptual Model}

The following section describes Diabetes Morning as it is structured around the Performance Improvement Model $^{20}$ adapted from the United Way's Program Outcome Model (see Figure 1). ${ }^{21}$ Using this framework, programs are designed to measure the benefits the people derive from their involvement in program activities. The description of Diabetes Morning's adaptation of the United Way model is summarized in Table 1 and includes the program's objectives, inputs, activities, outputs and outcomes.

Figure 1: United Way Program Outcome $\mathrm{Model}^{21}$

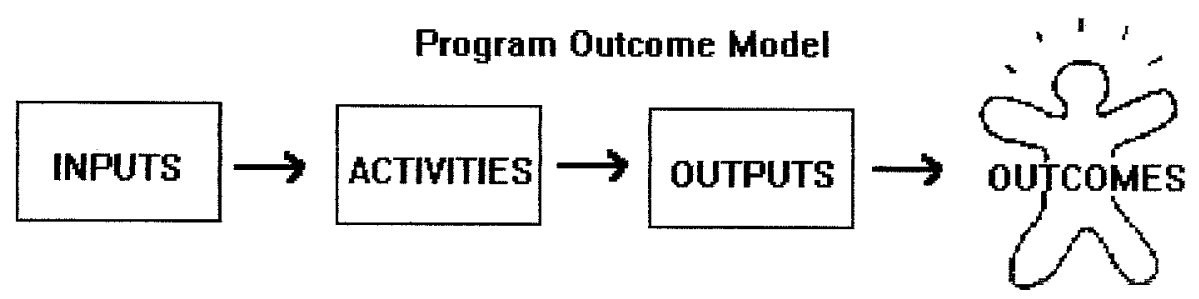


Table 1: Structure of Diabetes Morning based on the "Performance Improvement Model" $"$ (adapted from Diabetes Morning program documentation)

\begin{tabular}{|l}
\hline "Performance Improvement Model" \\
\hline - Participants will learn to plan and prepare low-cost diabetes-friendly meals and snacks
\end{tabular}

- Participants will gain a greater understanding of diabetes management and control through informal education sessions and discussions with diabetes educators.

\begin{tabular}{|c|c|c|c|}
\hline $\begin{array}{l}\text { INPUTS } \\
\text { (Resources) }\end{array}$ & $\begin{array}{c}\text { ACTIVITIES } \\
\text { (Services) }\end{array}$ & $\begin{array}{c}\text { OUTPUTS } \\
\text { (Products/quantifiable) }\end{array}$ & $\begin{array}{l}\text { OUTCOMES } \\
\text { (Benefits to the } \\
\text { people/changes) }\end{array}$ \\
\hline $\begin{array}{ll}\text { - } & \text { Money }(+) \\
\text { - } & \text { Time/personnel } \\
& (+) \\
\text { - } & \text { Facility }(+) \\
\text { - Advertising }(+) \\
\text { - Materials }(+)\end{array}$ & $\begin{array}{l}\text { - Meet monthly } \\
\text { - Cook } \\
\text { - Share } \\
\text { - Take home } \\
\text { - Advocacy } \\
\text { - Teaching } \\
\text { - Facilitation }\end{array}$ & $\begin{array}{l}\text { - Attendance } \\
\text { - Regular } \\
\text { - Irregular } \\
\text { - New participants } \\
\text { - Increased \# } \\
\text { - Friends/relatives } \\
\text { - Recipe/info sheets } \\
\text { dispersed } \\
\text { - \# of Glucometers } \\
\text { - \# Used glucometers } \\
\text { - Advocacy needed } \\
\text { - \# of participants } \\
\text { - \# Accessing RUH/ } \\
\text { St. Paul's Hospital } \\
\text { education programs } \\
\text { - \# Target population } \\
\text { - \# Outside target } \\
\text { - } \text { population } \\
\text { Use of } \\
\text { Transportation } \\
\text { allowance } \\
\text { allowance }\end{array}$ & 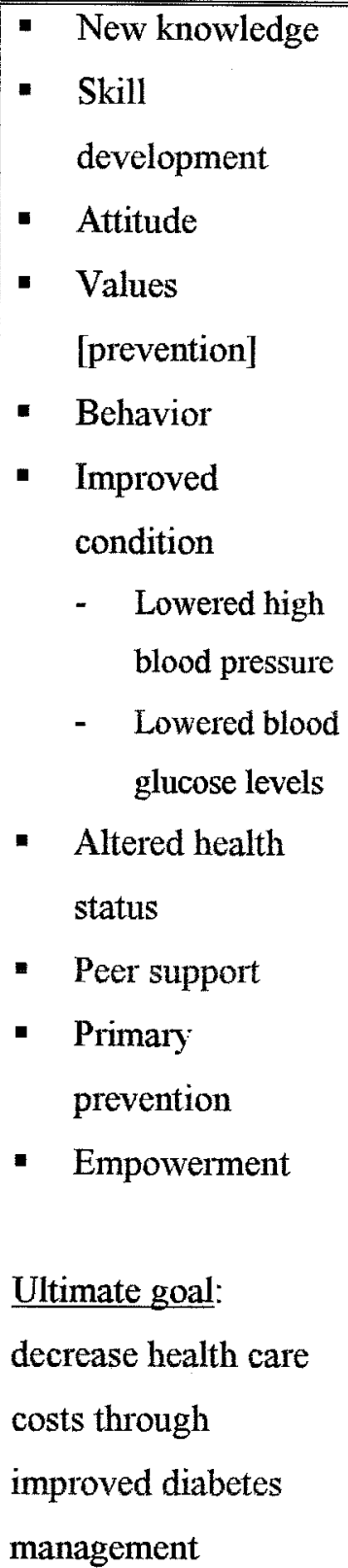 \\
\hline
\end{tabular}

${ }^{\ddagger}$ The material in this table is derived directly from program documentation. 


\subsubsection{Program Objectives}

The following objectives were stated when Diabetes Morning was first developed:

1. Participants will learn to plan and prepare low-cost diabetes-friendly meals and snacks, and

2. Participants will gain a greater understanding of diabetes management and control through informal education sessions and discussions with diabetes educators.

\subsubsection{Program Inputs}

Inputs are "resources dedicated to or consumed by the program."20 Inputs utilized by Diabetes Morning include money, time and personnel, the facility, advertising, and materials (see Table 1). Saskatoon Community Clinic provides one nutritionist and the Clinic's Health Promotion committee pays for food, bus tickets, taxi fare and childcare. A dietitian and a diabetes educator are provided by DEC of Saskatoon District Health (SDH). The West Side Community Clinic kitchen is used and has been chosen for its comfort, safety and accessibility. The program was initially advertised to potential participants using posters, letters and phone calls. Doctors from West Side Community Clinic referred their patients to the program. Materials include recipes, blood glucose monitors, educational videos and door prizes.

When the list of inputs was developed, the constraints upon them were also recognized. For example, 12 to 14 participants stretch the limitations of the kitchen's capacity. The program also identifies constraints associated with characteristics of the participant. For example, life's challenges can inhibit the participants' abilities to make 
changes, while language and cultural barriers may challenge communication. Financial barriers can also affect the ability to buy food and family members may influence food choices.

\subsubsection{Program Activities}

Participant-directed services (activities) as listed in Table 1 and described below, are "what the program does with the inputs to fulfill its mission." 20

- The women gather at the West Side Community Clinic to cook together. They cook diabetes-friendly recipes of their choice for about two hours, and then share lunch together before taking home the meals they prepared. Consequently, the participants learn to make affordable healthy food choices and control portion sizes.

- The women direct the learning/teaching sessions through informal discussion. Staff pass on their knowledge about topics such as caring for eyes and feet, the proper use of blood glucose meters, sugar equivalency of foods, and diabetes-friendly meal planning.

- Staff members facilitate sharing among participants about what they already know about managing diabetes. Participants are also encouraged to seek further knowledge by attending individual counseling sessions at St. Paul's Hospital or the Diabetes Education Centre at Royal University Hospital.

- Advocacy for support may occur between staff, participants, physician, Social Services, and/or Indian Affairs to purchase blood glucose meters and to increase the special dietary allowance for some participants. An alliance with a local drug store has been established to supply the required meters. 


\subsubsection{Program Outputs}

The outputs of the program (see Table 1) are viewed as a direct product of program activities. ${ }^{20}$ For example, the number of people attending Diabetes Morning sessions is an output indicator. Other output indicators include the number of: people who attend the program on a regular basis; new participants drawn into the program; participants who bring friends or relatives; recipes/information sheets distributed; glucometers acquired and used; people for whom advocacy is necessary; participants who access St. Paul's and/or Royal University Hospital programs; people outside the target population who attend sessions; and people who use transportation and childcare allowances.

\subsubsection{Program Outcomes}

The outcomes of the program (see Table 1) are recognized as the potential benefits or changes for the participants as a result of attending Diabetes Morning. ${ }^{20}$ The ultimate outcome is decreased health care costs through improved diabetes management. Intermediate outcomes include new knowledge and skills acquired, changes in attitude and behaviors, new values, improved condition/altered health status, peer support, primary prevention and empowerment. Improved health status can be measured, in part, by changes in glycated hemoglobin ${ }^{\S}$ and blood pressure over time.

New skills relating to diabetes management and control would be evident in behaviors such as increased use of glucometers and closer adherence to diet. Participants

\footnotetext{
$\$$ Glycated hemoglobin indicates the quality of control over blood glucose levels over an extended period of time averaging 8 to 12 weeks. Acceptable readings for persons with diabetes are between 4.5 and $8 .{ }^{13}$
} 
may start eating a larger variety of foods, serve different foods to their families and make healthier lifestyle choices such as taking part in physical activity and eating a healthier diet. If medication is required, participants may learn to use it more appropriately. They may begin to use their blood glucose meters more regularly, and maintain a more constant blood sugar level within the normal range. Their condition may improve with fewer crises and feeling better in general. Other health problems that may or may not be related to diabetes may also improve.

Attitude changes are described as covering a multitude of areas such as acceptance of diabetes, increased confidence in one's ability to make a difference in one's condition, and seeing that one is able to satisfy one's own needs as well as one's family's needs. Program documentation states that participants may become more hopeful and optimistic as they learn more about diabetes care and dispel myths such as insulin use being a last resort. A change in attitude or belief about insulin use can encourage values like preventing disability and other complications of diabetes.

Finally, peer support is projected to strongly impact the outcome of the program. New relationships may form and knowledge that one is not alone in experiencing the challenges associated with the disease can ease feelings of isolation. Participants may pass information on to others and become a role model for family and community members. Ultimately, they will feel empowered that they have control over the disease.

\subsection{Program Records}

Records are kept about individuals who join the program and about program activities. Individual records include general, medical, and progress information. Records about the program include debriefing notes and problem management. 


\subsubsection{Records about Individuals}

Information about individual participants is recorded on a two-sided form (see Appendix A): General and Medical Information on one side and Progress information on the other side.

The General and Medical Information form includes the date when the participant is assessed for the program, the person's name and address as well as the name and address of her/his physician. A "yes/no" response is recorded for the presence or absence of hypertension, altered lipids, other health problems, mobility difficulties, limits to exercise, whether they have attended a foot care session, own a glucometer, need advocacy to obtain a glucometer, need advocacy for social assistance program (SAP) increase, need for transportation/childcare, and whether or not the person brings family member[s]. There is also space to list additional health problems and for additional comments to be recorded.

The Progress Information form notes information about medications. This side of the form also includes spaces to enter the date, blood pressure, lipid values, blood sugar levels, and additional comments. Blood sugar levels include: glycated hemoglobin (the percentage of glucose within the red blood cells, which must be tested in a lab), Spot (glucose levels in the blood without fasting), and Fasting (glucose levels in the blood after a fasting period). 


\subsubsection{Records about the Program}

The program records form is also two-sided and filled out by program staff (see Appendix B). One side contains debriefing notes about program activities and inputs and the other side is devoted to documentation of problem management.

Diabetes Morning Debriefing Notes include the date of the session, location, number of people who participated and the number of guests, if any, accompanying the participants. A guest could potentially be a visiting family member or other family and friends who do not usually attend the program. Staff and volunteers who are present are also recorded. Eight topics for documentation are listed in a table on this form which include: listing the snacks that were provided, recipes that were prepared, education component delivered for the monthly session, costs for groceries, childcare and transportation paid, door prizes given, next month's menu and snack, resources used, and participants' request for resources.

The problem management side of the form is used to "describe any problems reported by participants in or out of group session that needed individual attention (e.g. Problem with diabetes management, and/or personal issues [such as] housing, lack of food, problems with family, etc...)."

\subsection{Diabetes Morning Program Focus Group Results}

In the fall of 1999, when Diabetes Morning first began, program staff conducted a focus group with 16 women who were attending the program. The main objective of the focus group was to gain insight into the participants' experiences and thereby develop outcome measures. While the information gained from the focus group is useful, it is not 
sufficient for developing outcome measures. Basically, the focus group results indicate what the participants believe they need to be healthy and what they expect from attending Diabetes Morning. Responses were shared by 14 of these 16 women and are presented in Table 2.

Table 2: Focus group ( $N=14$ ) results based on the five most important statements chosen by the participants and rated by program staff and associated with projected outcomes (adapted from program documentation)

\begin{tabular}{|c|c|c|c|}
\hline I come to Diabetes Morning... & $\mathbf{N}$ & $\%$ & Outcome Measure Categories \\
\hline To learn what to cook & 10 & 71 & Skill development \\
\hline To leam what to eat & 9 & 64 & New knowledge \\
\hline To share information with others & 9 & 64 & Peer support \\
\hline To learn how to eat & 8 & 57 & New knowledge \\
\hline Help prevent us from feeling we're alone & 6 & 43 & Peer support \\
\hline To share feelings and thoughts & 5 & 36 & Peer support \\
\hline To sample new recipes & 4 & 29 & New knowledge \\
\hline Help me know how to prevent me getting diabetes & 4 & 29 & Values \\
\hline Take away fear, anger, why me feeling & 3 & 21 & Attitude \\
\hline Help family cook better meals & 3 & 21 & $\begin{array}{l}\text { Skill development/ behavior/primary } \\
\text { prevention }\end{array}$ \\
\hline Develop self confidence & 2 & 14 & Attitude/Empowerment \\
\hline Feel less discouraged- its an uplifting experience & 1 & 7 & Attitude \\
\hline To eat & 0 & 0 & \\
\hline What I need to be healthy is... & $\mathbf{N}$ & $\%$ & Outcome Measure Categories \\
\hline Eating properly portioned foods & 10 & 71 & New knowledge/ behavior \\
\hline Exercise & 10 & 71 & Behavior \\
\hline See doctor regularly & 8 & 57 & Behavior \\
\hline Enough rest & 7 & 50 & Behavior \\
\hline Look after your feet and eyes & 7 & 50 & Altered health status \\
\hline Blood testing & 7 & 50 & Skill development \\
\hline Friends/company & 5 & 36 & Peer support \\
\hline Cleanliness & 4 & 29 & Behavior \\
\hline Label reading, what's in food & 4 & 29 & Skill development \\
\hline Affordable food & 2 & 14 & Primary prevention \\
\hline Quit smoking & 1 & 7 & Behavior \\
\hline Not using a large amount of alcohol & 0 & 0 & Behavior \\
\hline
\end{tabular}


Participants were involved in an exercise to generate a list of things they feel make a difference in their health and well being and to have participants identify those outcomes that would make them think Diabetes Morning is a success. Two main questions were posed: (1) "I come to Diabetes Morning to...?" and (2) "What I need to be healthy is...?" After brainstorming a list of possible outcomes, the women were asked to choose five of the answers that were the most important to them. Later the staff associated the women's responses with projected outcomes from the program model.

Additional questions were used as prompts: "Are there other people with whom you share this information?" "For those of you who have attended Diabetes Morning before, are there any things that you do different now?" "Identify five ways in which Diabetes Morning can help you the most."

Based on the responses of the 14 women, program staff found that the women come to Diabetes Morning to learn and share knowledge about how to eat a healthier diet. Peer support was also an important part of the program. Participants reported that what they need to be healthy is to engage in health altering behaviors such as eating properly portioned foods, exercising, seeing the doctor regularly, getting enough rest, looking after their feet and eyes and testing their blood. Staff categorized these responses by projected outcome measures listed in Table 1: new knowledge; skill development; attitude; values; behavior; improved condition; altered health status; peer support; primary prevention; and empowerment.

The focus group captured some of the needs and expectations of participants in managing diabetes when the program first started, expectations of themselves and Diabetes Morning. The present study moves beyond expectations and is designed to capture domains for changes that have occurred over time to the health and well-being of the participants. Knowledge about the participants' experiences with the program, what 
they understand about managing diabetes because of the program, and the impact that they perceive the program has had on their health and well-being can help to define outcome indicators. 


\section{CHAPTER THREE}

\section{METHODOLOGY}

\subsection{Introduction}

In this section, I describe qualitative methods as they apply to the present study, issues of rigor in qualitative research, and the process that was followed in order to conduct the study.

\subsection{Qualitative Methods of Enquiry}

Qualitative research methods are very useful in determining the impact Diabetes Morning has had on the participants' health and well-being. Understanding the program's strengths and weaknesses from the perspective of the participants is a necessary step toward identifying the overall dynamics of the program. A qualitative method of enquiry is an appropriate venue for exploring the multiple realities respectful

of the particular experiences of the participants. ${ }^{22}$ It allows me to go beyond the projected or intended outcomes of the program to explore outcomes identifiable through the experiences of the participants and stories they share about the impact the program has made on their health and well-being,

The methods of enquiry employed in this study include individual interviews, a group interview, and abstracting attendance rates. Each method carries its own strengths and limitations. Thus, using more than one method of enquiry allows me to pick up on information that might otherwise be missed. ${ }^{22}$ For example, a group discussion can 
encourage dialogue and reflection on a given topic. As is common with experiential learning, knowledge can be acquired without a conscious awareness that it has occurred unless the opportunity to reflect on the matter is present. When a group of people begin to reflect, the shared experiences can elicit more information than in a one-on-one interview. However, a one-on-one interview allows individuals to share information that they may not feel comfortable sharing in a group setting.

Abstracting information such as attendance rates also has its strengths and limitations. Attendance rates about how long and how often the participants have attended Diabetes Morning indicate the amount of exposure these individuals have had to the program activities. A limitation that is characteristic of historical records is that they are often incomplete and should not be relied on as the sole source of information.

\subsection{Rigor in Qualitative Research}

According to Leininger, qualitative researchers come to know about the phenomena of interest in a different way than quantitative researchers and this different focus appears to be grounded in the differing assumptions between them. Thus, establishing rigor should be grounded in the appropriate assumptions as error is prevented in different ways for each paradigm. ${ }^{23}$

Lincoln and Guba present four categories for evaluating the rigor of qualitative research and describe their relationship to more commonly known criteria used to evaluate quantitative research. ${ }^{22}$ These categories are truth value/credibility, applicability, consistency and neutrality. Truth value, also referred to by qualitative researchers as credibility, is related to the issue of internal validity in quantitative research. The question to be answered in this category is "Are we capturing what we set 
out to capture?" An analysis of qualitative research should ask if multiple perspectives

were recognized. Triangulation, the use of more than one method of data collection, can

be used to increase the credibility/truth value of the results.

Table 3: Explanation of Criteria and Strategies For Evaluating Rigor in Qualitative Research (adapted from Lincoln \& Guba 1985; Leininger, 1994) ${ }^{22,23}$

\begin{tabular}{|c|c|c|}
\hline CRITERIA & EXPLANATION & $\begin{array}{c}\text { STRATEGIES FOR } \\
\text { ADDRESSING } \\
\text { CRITERIA }\end{array}$ \\
\hline $\begin{array}{l}\text { 1. Truth Value/ } \\
\text { Credibility }\end{array}$ & $\begin{array}{l}\text {-Are we capturing multiple } \\
\text { realities? } \\
\text {-Comparable to internal } \\
\text { validity in quantitative } \\
\text { research. }\end{array}$ & $\begin{array}{l}\text { Triangulation: Using more } \\
\text { than one method of data } \\
\text { collection to increase } \\
\text { credibility } \\
\text { Recurrent Patterning: } \\
\text { Cumulative occurrences of } \\
\text { patterns (Example: } \\
\text { triangulation) } \\
\text { Prolonged period of time } \\
\text { spent with participant: } \\
\text { Spending time in the } \\
\text { context being investigated } \\
\text { Participant feedback: Going } \\
\text { back to the participants for } \\
\text { their input into the } \\
\text { interpretation of the data }\end{array}$ \\
\hline $\begin{array}{l}\text { 2. Applicability/ } \\
\text { Confirmability }\end{array}$ & $\begin{array}{l}\text {-How applicable are the } \\
\text { findings in similar settings? } \\
\text {-Comparable to external } \\
\text { validity in quantitative } \\
\text { research. }\end{array}$ & $\begin{array}{l}\text { Meaning in Context: } \\
\text { Contextualization of } \\
\text { information }\end{array}$ \\
\hline $\begin{array}{l}\text { 3. Consistency/ } \\
\text { Transferability }\end{array}$ & $\begin{array}{l}\text {-Do these multiple realities } \\
\text { exist in similar settings? } \\
\text {-Comparable to external } \\
\text { validity in quantitative } \\
\text { research. }\end{array}$ & $\begin{array}{l}\text { Saturation: "Thick data" } \\
\text {-The same information is } \\
\text { repeated several times in the } \\
\text { data set } \\
\text { Also, Triangulation }\end{array}$ \\
\hline 4. Neutrality & $\begin{array}{l}\text {-How free is the study from } \\
\text { bias? } \\
\text {-Comparable to objectivity } \\
\text { in quantitative research. }\end{array}$ & $\begin{array}{l}\text { Audit Trail: Personal } \\
\text { reflections on the process } \\
\text { with self or others to control } \\
\text { for bias (example: } \\
\text { journaling) }\end{array}$ \\
\hline
\end{tabular}


In qualitative research, applicability is related to external validity. In evaluating qualitative research, one would ask how applicable the findings would be in a similar setting. The results of a qualitative analysis should not be mistaken as a singular truth but as a variety of instances in an ever-changing process.

Consistency is related to the term reliability. In qualitative research, consistency in findings refers to consistently finding that the same or similar multiple realities exist in the same setting or similar settings. Again, triangulating information through more than one form of data collection can also increase the capacity to verify consistency.

Finally, neutrality is related to the quantitative evaluation criterion called objectivity. Neutrality refers to freedom from bias. Qualitative researchers attempt to achieve neutrality by reflecting on their own biases with other researchers or through journals and by spending time with the participants. ${ }^{22,23}$ Recording subjective interpretations of events can keep the qualitative researcher conscious of his/her potential biases. Leininger suggests that the researcher should return to the participants for their input on the interpretation or analysis of the data as a way to confirm the findings and establish neutrality. ${ }^{23}$

In general, strategies used to improve the rigor of the study include triangulation, time spent with the participants and reflection. More than one method was utilized for collecting information about the experiences of the women who participate in the Diabetes Morning program to increase the credibility of the findings. The combination of these methods strengthens the overall trustworthiness, consistency and applicability of the findings. Neutrality was attempted through personal reflections about the process and about my own personal biases as well as a prolonged period of time, 1.5 years, spent with the women in the Diabetes Morning Group. Field notes were used to help interpret transcripts from the interviews and not analyzed as participant-observation data. 
Transcripts were returned to the women for feedback before interpreting the findings. Transcripts for the group interview were returned to participants of the group interview while transcripts from the individual interviews were returned to the individual who participated in the interview.

\subsection{The Process}

\subsubsection{The Presence of the Researcher}

According to Wendy Sword, a qualitative researcher serves as a "research instrument" and needs to account for the presence of self within the research process as a means of strengthening the researcher's integrity and in an attempt to obtain neutrality. She states "no research is free of the biases, assumptions, and personality of the researcher... [and that] we cannot separate self from those activities in which we are intimately involved." ${ }^{24}$ Thus, I recorded my observations regarding my association with Diabetes Morning and reflected on these observations in an attempt to remain cognizant of my presence within the research process. Also, I was cautioned by my committee not to delve too deep into the literature before hearing the stories of the women in Diabetes Morning. Thus, literature pertaining to living with diabetes was reviewed after the analysis was completed.

I chose this project because of my interest in learning about the various aspects of health promotion programming. In particular, I am interested in exploring programs that address a wide range of health determinants including socioeconomic status, gender, and culture. This project involved women, mostly Aboriginal women, some of whom face socio-economic challenges. 
The women I have met while participating in Diabetes Morning are very welcoming people with an open and accepting nature. While I was writing up the findings, I continued to attend the program to cook with them, to talk with them, and to learn with them. They have shown me the comfort of their humor. They have also shown me that, even though it is not always easy to find the energy to attend the program, they come together and support each other. They have taught me about teamwork, too. Some of the women who are feeling better than others on a given day carry the workload for those who are less well so that everyone can take food home.

While listening is very important, reflection is like listening again. I have experienced the value of reflecting on the times I was with the group and journaling my experience. As I wrote, I asked myself questions about what my observations meant. As Wendy Sword suggested, ${ }^{24}$ I continued to reflect about the meaning I attributed to my experiences with the group.

The women's stories are a gift of wisdom gained from their experiences of living with diabetes. I am also inspired by the possibilities that underlie health promotion initiatives, like Diabetes Morning, that evaluate the process from the perspective of the people "whose health is being addressed." 25 Such practices allow us to move beyond the limitations of what we think we already know about groups of people by involving them in evaluation so as to inform the process. The women who shared their stories have done precisely that: informed the program process by sharing what they have learned. Their stories can teach various stakeholders about service delivery that is relevant to and appropriate for their lives and their communities. 


\subsubsection{Literature Review Process}

A literature search was performed before data collection and after analysis of the findings. Databases used in searches include Medline, Pubmed, Psychinfo, Eric and Bison between 1967 to the present. Literature was also obtained in consultation with committee members. Due to limited publications related to Aboriginal diabetes education programs, materials were also gathered during the initial search through membership with the National Aboriginal Diabetes Association and through participation in the first national conference. As part of the process, I was cautioned by my committee not to delve too deep into the literature before hearing the stories of the women in Diabetes Morning. Thus, literature pertaining to living with diabetes was reviewed after the analysis was completed.

Searches performed after data analysis were geared toward living with diabetes and contextual indicators. I also reran a search on Medline, Pubmed, Psychinfo and Eric in January 2003 in hopes of finding more information about Aboriginal diabetes education programs. I noted no change.

\subsubsection{Traditional Protocol}

As a non-Aboriginal researcher working with Aboriginal women, I understand the importance of increasing my awareness and understanding of Aboriginal cultures. To help me with this, I sought the guidance of a First Nations Elder, beginning May 2000, when the idea for this project arose. Deiter \& Otway ${ }^{26}$ addressed research as a spiritual contract in an Aboriginal women's health project. They followed traditional protocol to honour this contract during the process of their project, and I followed a similar process 
in this study. Individual experiences vary, but the general process is captured by Deiter and Otway.

Before I took part in traditional protocol, I was referred to the book, "The Sacred Tree, ${ }^{27}$ to learn some background information about Aboriginal traditions. Even though the book presents information in an easy-to-follow format, the information reflects the complexities and richness of Aboriginal traditions. To illustrate this, here is the opening paragraph to the story of The Sacred Tree:

"For all the people of the earth, the Creator has planted a sacred tree under which they may gather, and there find healing, power, wisdom and security. The roots of this tree spread deep into the body of Mother Earth. Its branches reach upward like hands praying to Father Sky. The fruits of this tree are the good things the Creator has given to the people: teachings that show the path to love, compassion, generosity, patience, wisdom, justice, courage, respect, humility and many other wonderful gifts." $(\text { p. } 7)^{27}$

\subsubsection{Point of Entry}

I attended Diabetes Morning sessions from September 2000 to January 2002. After the staff introduced me, I explained that my presence had been endorsed by the program, in cooperation with my thesis committee; that I had been asked to interview participants of the program about their experience regarding Diabetes Morning; and that I was under the guidance of an Elder/teacher. On my fourth visit, I explained to the group that I was intrigued by the notion that their feedback was being requested to inform program development through their stories about how well the program is going and where it can be improved. I shared a gift with the women, inviting their participation, and asked them how they would like to be involved in the process. I suggested one-onone interviews, sharing as a group, or both. The group agreed that it would be a good idea to have both options. For example, one woman said she may not be able to attend 
the group session but could make an appointment for an individual interview. Also, if there was information that a person would like to share privately, the option for a personal interview was available.

\subsubsection{Participants}

Participants were recruited from among approximately 30 women, ranging from age 40 to 90 , who participate in the Diabetes Morning program. Selection was based on the desire of the person to participate in the study. The number of visits a person has made to the program, the length of time they have belonged to the program or whether or not they still attended the program did not restrict participation in the study. Those who attend every session may have a different experience with the program than those who attend sporadically or discontinued coming. It is important to capture these differences. People who have only attended the program within the last month or two as opposed to the person who has been present from the onset of the program, could bring different perspectives to understanding the program through their experiences.

\subsubsection{Funding and other Support for the Research}

The Community-University Institute for Social Research (CUISR) internship provided approximately $\$ 3000$ over a six-month period (November 1,2000 to April 30 , 2001) to subsidize my expenses. Cab fare and $\$ 10$ in childcare was paid for by the Diabetes Morning program to each participant who agreed to participate in the study. Diabetes Morning also provided space at West Side Community Clinic for the interviewing process. 


\subsubsection{Gathering Information}

The methods used for collecting data included a group interview, individual interviews and extracting attendance rates from program records. In an attempt to obtain neutrality, open-ended questions were used to guide the women through the interview process. The process involved building on information that has already been obtained, beginning with the group interview, followed by individual interviews and a review of attendance records. The information gathered from the group interview was used to enrich the individual interview process. In the individual interviews, I shared the preliminary data from the group interview with the participant, providing her with an opportunity to expand on this information. After transcription of the group and individual interviews was complete, a copy of the transcript was returned to participants for feedback. Permission for release of this information was requested and received.

Interviews occurred between May and June 2001. The group interview took place at West Side Community Clinic during a regular Diabetes Morning session. Program staff mailed the invitation to attend the group session to all participants. After the group interview, participants were invited to contact me if they wanted to share anything further with me. Others who had not attended the group interview were called and invited to participate in an individual interview. When they accepted the invitation, they were asked where they would like to meet. Individual interviews took place in the individual's home or in one case, a quiet restaurant.

Open-ended questions were used for the group interview and individual interviews. Once a dialogue began to flow, I led into more specific questions. Prompts were used in instances when answers were unclear, to encourage further reflection. However, prompting did not occur without using other interview techniques including 
silence (allowing time for the participant to reflect before responding) and non-technical language (e.g., blood testing rather than glucose monitoring) and non-threatening language (e.g., body language; a patient, friendly and polite manner; and asking permission during the various stages of enquiry).

During the introduction stage of the group interview, I explained that a sharing stone $^{* *}$ would be passed around in order to respect each other's uninterrupted time to share. I asked them to share a little bit about themselves such as where they are from and how long they have had diabetes. The rest of the group interview was focused on questions about what has changed for each of the women since they began to attend the program. They were asked to think back to when they first started to come to Diabetes Morning and what it was like for them. Then they were asked to think about today and what it's like for them when they come to Diabetes Morning, if anything changed and what that might be. Then, I asked them to think about their health and well-being; if they experienced any change since they started to come to Diabetes Morning; and if they think that coming to the program had anything to do with this, and how. I concluded by asking if they had any other comments or suggestions.

During the individual interview process, the same questions were asked and I shared information that I had gathered from the group interview since none of the participants of the individual interviews had taken part in the group interview. Conversations were recorded except in those cases where permission to do so was not received from the individual woman or they appeared uncomfortable with the tape. For example, one woman appeared withdrawn, so I suggested that we turn off the tape

\footnotetext{
"* A sharing stone is used in traditional sharing circles: when passed around, the person who holds the stone is given an uninterrupted time to speak.
} 
recorder. She opened up more after I turned off the tape and took notes. In either case, the transcripts were returned for their review and approval.

Attendance records are kept for each session of Diabetes Morning. After the interviews were complete, I obtained program information about when each woman started the program and how often she had attended. This information was used to clarify the frequency and duration of involvement of the participants.

\subsubsection{My Reflections}

I reflected on my own experiences, insights and questions about what I experienced when I was present at the Diabetes Morning program, performing interviews and obtaining information about attendance. The reflections raised my awareness of my presence as the researcher during the process of data collection and analysis in an attempt to obtain neutrality.

\subsubsection{Consent}

This study was approved on ethical grounds through the University of Saskatchewan Behavioural Sciences Research Ethics Board prior to conducting the study. Consent was obtained from participants by their signature on the appropriate consent form (see Appendix E and F). Large print and plain language were used. The information that is on the consent form was presented orally to the whole group in the group interview and to each individual in the individual interviews. Those women who chose to participate were asked to sign the consent form after it had been explained to them. Debriefing details were given to them on a separate form (see Appendix $G$ ). The consent form was signed in duplicate: one copy for the participant to keep for their 
records and one for me. Transcripts were returned to the participants for their review and release. At this time, they were asked to sign a transcript release form (see Appendix H). 


\section{CHAPTER FOUR}

\section{FINDINGS}

\subsection{Introduction}

The purpose of the present study was to determine the impact that Diabetes Morning has had on the participants' health and well-being based on their experiences and suggest possible outcome indicators based on their stories. The experiences of the women who shared their stories are presented in this chapter, which includes the impact of the program on their health and well-being. Their stories also include experiences describing the context of their lives in relation to living with diabetes. Possible outcome indicators are suggested in Chapter Five.

The first significant finding that further framed the analysis was a fundamental relationship that exists between the context of one's life and the subsequent ability to manage diabetes. In an attempt to capture the rich data about living with diabetes, the findings are presented in three categories beginning with demographic information about the participants and their attendance. This is followed by two general themes: the context of their lives and the impact of the program. ${ }^{\dagger \dagger}$ Stories about the context of their lives are presented in five sub-themes: diagnosis; treatment; self-management; conditions of life related to the experience of diabetes; and the impact of relationships related to the experience of diabetes. Stories about the impact of the program are presented using the sub-themes: overall impact; cooking; information and support sharing among participants; and information and support sharing with staff.

${ }^{\dagger}$ Themes and sub-themes were decided in agreement with thesis committee members 


\subsection{Participants' Attendance}

Sixteen women from the Diabetes Morning program participated in this study.

Selection was based on the desire of the person to participate. Eleven women participated in the group interview and an additional 5 women participated in individual interviews. Total months since first attendance ranged from 3 to 22 months. Total visits ranged from 1 to 22 visits. Attendance rates were calculated per individual using total months since first attendance per individual divided by the total visits per individual (see Table 4).

Table 4: Participants' Attendance Rates

\begin{tabular}{|l|r|r|r|}
\hline \multicolumn{1}{|c|}{$\begin{array}{c}\text { Participant } \\
\text { ID Number }\end{array}$} & $\begin{array}{c}\text { Number of months } \\
\text { since first } \\
\text { attendance }\end{array}$ & $\begin{array}{c}\text { Number of } \\
\text { monthly meetings } \\
\text { attended }\end{array}$ & Attendance rate \\
\hline NINE & 22 & 22 & $100 \%$ \\
\hline SLX & 22 & 19 & $86 \%$ \\
\hline SEVEN & 22 & 19 & $86 \%$ \\
\hline TWO & 22 & 17 & $77 \%$ \\
\hline FIVE & 18 & 13 & $72 \%$ \\
\hline THIRTEEN & 13 & 9 & $69 \%$ \\
\hline SIXTEEN & 22 & 15 & $68 \%$ \\
\hline ONE & 22 & 14 & $64 \%$ \\
\hline TEN & 21 & 13 & $62 \%$ \\
\hline FOUR & 21 & 11 & $52 \%$ \\
\hline FOURTEEN & 22 & 11 & $50 \%$ \\
\hline TWELVE & 14 & 7 & $50 \%$ \\
\hline EIGHT & 9 & 4 & $44 \%$ \\
\hline THREE & 3 & 1 & $33 \%$ \\
\hline ELEVEN & 21 & 4 & $19 \%$ \\
\hline FIFTEEN & 22 & 4 & $18 \%$ \\
\hline
\end{tabular}

Attendance rates ranged from $18 \%$ to $100 \%$. Out of a possible 22 months, the majority of the women first attended the program $21(\mathrm{n}=3)$ and $22(\mathrm{n}=8)$ months prior to participating in the present study. Two of these eleven women attended $18-19 \%$ of the 
sessions with 2 to 4 months since their last visit. Eight of these eleven women attended Diabetes Morning sessions between 62 to $100 \%$ of the time; one attended $50 \%$ of the 22 sessions. The other five of the sixteen women first attended Diabetes Morning 3 to 18 months prior to participating in the present study with attendance rates ranging from 33 to $72 \%$.

\subsection{The Context of their Lives}

The stories that the women shared about their experiences with diabetes included experiences with diagnosis, treatment and self-management, conditions of life affecting their ability to manage the disease, as well as the impact of relationships in managing diabetes and preventing further complications.

\subsubsection{Diagnosis}

Many of the women shared how long it had been since they were diagnosed with diabetes. Aside from the occasional response of "a long time," most women reported either the year or their age when they were diagnosed. Duration of time with diabetes ranged from 2 years to 30 years. Reported age of onset was when the woman was either in her early twenties or "when [she] got older." Many of the participants shared stories of growing up with diabetes in their families and communities while others reported that they didn't know about diabetes until the last decade.

The women's stories reveal a sense of being misunderstood at times by others who are not diagnosed with diabetes. One woman stated, "If it's not of your experience, it's hard to understand." Others don't always understand the symptoms of the disease 
and don't always know how to respond. As one woman stated, "When I'm feeling crabby, others don't see that I look sick, when I'm ready to pass out."

When health care practitioners use the term "chronic" to explain diabetes, one woman in particular associated this occurrence with no hope and with questions remaining unanswered:

"Mostly, I found out from other people... some of these [health care practitioners]... what they tell me, it doesn't sound right. Anything I tell them is chronic, I don't know why. I just want to find out about, to see about these things. There is no hope!"

The women shared how denial has also played a role in their ability to accept the diagnosis of diabetes. As one woman discussed her successes with managing the disease, she said that in order to be successful "...admitting diabetes is important." She also said that "... it takes time." Another participant stated:

"...how I had that denial. And it wasn't only me that had that denial; you know it was other people too. And that really helped me because I thought it was just me, you know, denying that I had diabetes... but it wasn't only me that was denying because most everybody I think goes through that denial period. It took me a long time to accept I had diabetes."

Others shared this sentiment at various stages of taking an active role in managing diabetes for themselves. Sometimes, finding excuses to not follow their management plan is a reality they have in common: "There are so many things going on in my personal life...I get caught up in telling myself lies, like I'm not doing bad."

When medication and diet have controlled blood sugar levels, the accuracy of the diagnosis is questioned:

"I don't know if I am a diabetic or not. I am taking a pill every morning and every time I go to see the doctor he says your [blood sugars are] level, like, you know, staying in one place but I still don't believe that I am diabetic. My mother, my sisters, none of them were [diabetic]. We didn't know [diabetes] in them days. I never heard about [diabetes] until I moved to Saskatoon and they all died before I come here and that was 
over 10 years ago. So, I don't know if I am a diabetic or not. But I just follow the crowd anyway."

Complications of diabetes are present in their lives and are sometimes feared by the women in this study. Many of them have had family members die or live life disabled from loss of limbs and eyesight. Thus, fear sets in when experiencing poor circulation, deteriorating eyesight, sugars out of control or blackouts. One woman said, "It's scary! It doesn't go away!" Other diagnoses include heart disease, high blood pressure, high blood cholesterol, TIA ${ }^{\ddagger}$, stroke, kidney problems (not specified) and another genetic blood disease:

"Last year when [my body] shut down, I go to [the doctor] and they stick me that time in the hospital. What a horrible time. I know how it feels when your body shuts down, on top of that I got diabetes. So I got two things in my system that don't really work proper."

In some cases, high blood pressure was recognized before diabetes, and associated with care giving or "always doing for others." Other complications that were recognized include having had large babies, increasing age, and, in one case, bouts with anorexia and overeating. The woman who experienced an eating disorder associated the shift from starvation mode to eating to excess with her inability to control blood sugar levels. Heredity was also recognized as a contributing factor. Thus, their stories reflect a family history of diabetes as well as its complications and treatment.

\subsubsection{Treatment}

The women's fears are not only associated with complications of diabetes, but also with the treatment of diabetes, most specifically fear of the needle. One woman

\footnotetext{
¥+ TIA is a transient ischemic attack, a term used to describe focal neurologic abnormalities with sudden occurrence and lasting $<24$ hours. One or more TIA often precede a stroke. ${ }^{2}$
} 
believed her father died because insulin (the needle) was administered in the hospital.

Another woman shared her fears:

"And it scares me...those needles I take... I just lost a sister not too long ago. She was on dialysis for many years, the one that just passed away. And her toes got her leg cut off, all her nails were black, and [she] just died."

When pills are prescribed, there doesn't appear to be the same level of uncertainty about taking the prescribed medication as when "the needle" is prescribed. Sometimes, when the needle was used, the amounts of insulin were modified: if the person was feeling sick, she would stop taking the needle altogether, decrease the amount taken, or increase the amount. In one case the woman was invited to inject another family member's prescription but she was aware that there are different types of insulin, and that her prescription might be different. However, she did report self-regulation of her insulin injections:

"I give myself more than what I am... supposed to. So, I do that on my own. I don't have a doctor tell me how many units to put. I don't go by him because I think I need more than that. I don't wanna tell him... I am supposed to take 10 units [of] one but it doesn't help, and 10 units [of] the other one. Doesn't help. So I put them up to 15 units... more than that even. It helps. And sometimes before long, then [blood sugars are] high."

In these cases, a health care practitioner was not consulted. And the reasons they gave for not consulting a health care professional related to services. For example, there was a tendency to not know which health care practitioner to trust. Waiting to get in to see someone is reported to be as long as 5 to 6 hours. Sometimes, white people who came later have been observed being taken into the office before the Aboriginal person. In a group, white people are spoken to, "but not the Indians." One woman reported exploring alternative nutritional care from a herbalist and entering a clinical trial as a last resort in an attempt to get more of the personalized care she felt she needed despite the fact that an experimental drug would be administered. 
Some of the women manage diabetes well by using insulin as prescribed and being monitored by a health care practitioner. Yet, even when insulin has improved their condition, most of the women remain apprehensive about using "the needle."

In those cases where the women received care, they reported the usefulness of tests that help them to stay on track, specifically the glycated hemoglobin test. Unlike the finger poke, this test measures a change in blood sugar levels over an extended period of time:

"Dr.__ jokingly said [the glycated hemoglobin test is] to test if you're telling the truth. So I thought I can't really fool 'em 'cause this month if I let it slide, it will show."

\subsubsection{Self-management}

While self-management included the women's experiences with treatment, they also reported other methods of self-management: monitoring blood sugar levels in relation to particular foods they eat, learning from others, self-care strategies and exercise.

Some individuals attempted to manage their blood sugar levels $s^{\text {s }}$ by monitoring blood sugar levels in relation to particular foods they eat. Some women measured their blood glucose levels after eating certain foods to identify whether or not that food has increased their reading. Eventually, they cut back monitoring their blood sugars to once every 2-3 days. On the other hand, there are women in the group who believed that their individual norm was much higher than levels based on medical advice:

"There are times I don't hardly eat, maybe take toast in the morning and a coffee and then it is still 14 and 15. I am supposed to be about 8 . You know,

\footnotetext{
${ }^{\$}$ On a daily basis, blood glucose levels can be tested by pricking the skin and testing the blood with a meter or strips. Medically recommended range for a reading is from 4 to $7 \mathrm{mmol} / \mathrm{L}$ before ingesting food. ${ }^{13}$
} 
everybody's different... Some people are between 5 and 7, I think I would be dead long ago!... They say, 'When you have diabetes you know, you have to [be] between 7 and 5.' That's not true! I am not a doctor but I know! ... and other people [know]! ... I totally disagree because that won't fit me... If I go down to 7 or 6 I kind of feel funny, you know... I get like shaky, sweaty, and...that kind of panicky thing... You can't tell a doctor something like that. 'It's probably your imagination,' he'd say. But everyone is different... It's my body and I should know how I feel."

The women reported learning from others with diabetes. They also learned by attending workshops like Diabetes Morning where health care practitioners are also present, from watching educational television programs, and from reading about taking medications and how to eat at celebrations. Most women desired written material.

Traditional celebrations are a challenge for one woman from the group who states she doesn't want to be disrespectful by not accepting food. But, "eating the hamburger first" allowed her to be able to eat less of the other foods. If she was asked about how she is eating, she shared some of what she has learned about her diet, such as using oil in bannock recipes instead of lard.

Some of the women reported an improved condition such as managed sugars, weight loss, and ulcers healing. These women were the most regular attendees of Diabetes Morning. They attribute their success to the program as well as to other approaches to self-care such as modifying their diet, increased exercise, eliminating alcohol and smoking, spending time with friends and keeping busy. Independence and employment were stressed as factors influencing their ability to care for themselves. The ability to care for one's self declined when employment and/or independence were lost or altered due to living with diabetes. 


\subsubsection{Conditions of life related to the experience of diabetes}

Some of the women reported limited access to low-cost diabetes-friendly foods as a barrier to diabetes management. The Food Bank is accessed by some of these women but does not provide enough diabetes-friendly foods such as fruits and vegetables for single people. A woman who must register as a single person because the children living at home are over the age of 18 receives a different and less appropriate selection of food for a diabetic diet than one who registers as a family with dependents under the age of 18 . The general experience is that families with younger children are the first to receive meats and fresh foods when they are available to the Food Bank, with singles not receiving any of these foods. This leaves a selection of highly refined starchy foods for the single person with diabetes. A program called Community Alive was available at one time to provide fresh fruits and vegetables to individuals who could not afford to purchase them. While the Good Food Boxes are recognized as an alternative, the money to pay for this cheaper alternative is not always available. However, one woman stated that the Good Food Box had been purchased for her by a health care practitioner.

While access to safe drinking water does not directly affect the women in the program who live in an urban setting, they expressed concern for their families and friends living on reserves where water is not easily accessible. This lack of a sufficient water supply directly affects their families and friends and indirectly affects the women's sense of well-being. The women in this group are affected by stressors from worrying about family and friends, which can result in further complications such as high blood sugar readings, hypertension and other complications of diabetes. 
4.3.5 The impact of relationships on the experience of diabetes

Relationships can be stressors and/or supports for the women attending Diabetes Morning. Care giving was often a stressor that had negative effects on the health of the individuals. Often, the women care for family members with the same disease that the women are attempting to manage for themselves. They care for parents and siblings who are disabled from diabetes and its complications and who eventually die from it. As well, many of the women care for their grandchildren and elderly parents.

Family and friends also provide support that helps to alleviate a sense of being alone with the disease. Some of the women enjoyed the Kokum's group ${ }^{* * *}$ made up of a group of Aboriginal grandmothers who meet regularly at the clinic to support their peers. Another woman finds her mother to be her best support. She shared the comforting words from her mother after her brother died from diabetes:

"When I found out I had sugar diabetes the doctor told me you know I was kind of scared and I was talking to my mom and my mom told me, 'Don't be scared. Just talk to him, I'll tell you what to do.' I was talking to mom. My Mom told me, 'You got to have exercise, walk around' and she says 'You will be okay...' She supports me and she said not to worry, 'you might get a little worried some days,' but she told me not to worry too much. She goes for a walk with me sometimes when she is not tired. Nice days we go for a walk. We go to the drug store to get my needles for sugar. And we walk and we talk. She always says 'Don't worry my daughter. You are still my baby so don't worry about your sugar you might get over it someday."

The adversity that the women faced and witnessed among their families and friends has provoked a desire in them to improve community access to services like Diabetes Morning in the urban setting as well as on reserves. At the same time, they strive to maintain a positive attitude. There was a desire to educate Chief and Council about the need to improve people's ability to manage diabetes. As one woman stated,

\footnotetext{
${ }^{* * *}$ Kokum is the Cree word for Grandmother.
} 
"We need to stop this epidemic." Despite adversity, some of the women have been able to manage diabetes in their lives. The reason that one woman gave is, "Recovering from diabetes is my priority over other life stresses."

\subsection{The Impact of Diabetes Morning}

Participants made several general comments attributing positive changes in their lives to their attendance at Diabetes Morning. As well, they made more specific comments about various aspects of the program, such as cooking, information sharing and sharing support among participants and by staff. A general positive comment that one woman made is:

"Diabetes Morning is a program I'd recommend to anyone who's got diabetes or anything similar to that, any illnesses at all because Diabetes Morning, I benefited from that and I'm happy that I'm part of the group and I will continue to go."

The women gave a variety of reasons for initially attending the program. Many began to attend after losing family members due to diabetes and its complications. Some came because their doctor sent them; others came because their friend brought them.

Others wanted to lower high levels of blood cholesterol, blood pressure, and blood sugars. Some wanted to change eating habits and lose weight. One woman was already attending many programs to manage diabetes including Diabetes Education Centre and The First Step Program, an exercise program designed to provide professional and peer support for individuals who have decided to become more active. Another woman decided to attend because she enjoys having the company.

The impact statements reveal benefits that the women reaped from attending the program. Some women claimed that regular attendance helped them to do better managing blood sugars and maintaining positive thoughts about their health-- "it feels 
good to go." The following statement was made in relation to weight loss that one

woman attributed to what she learned from attending Diabetes Morning:

"I noticed [weight loss] over the winter, like I was just, I don't know, I would... every time I would look in my cupboard to see what I had to make, I always had cooking oil and I didn't want to deal with that so I'd push it to the back "cause I didn't want to deal with fried stuff or oil."

Awareness levels about diet and exercise increased. For many, exercise and a nutritious diet have become an ongoing part of their lives. They report being more aware of the nutritional value of different foods, thus eating differently. One woman reported that if she prepared foods by following the recipes that she received from the program and by buying food in moderation, food costs decreased. There is an awareness of the benefits of exercise to manage blood sugars. Exercise has been integrated in many of their lives. For example, one woman reported climbing the stairs in the apartment building during the winter when it was not so easy to get out while babysitting her grandchildren.

Understanding what diabetes is about, what it is doing to their bodies, has helped many of these women come to terms with having diabetes. For some, they have accepted diabetes as a way of life:

"Well I can just say that since coming here I have learned to live with my problems, like the diabetes part anyway, to have it part of my life because there is no cure for it so I might as well have to live with it so I just put it with whatever else I do and it goes with my list of everything that needs to be done."

Illustrating another positive impact, some women noted how friendships have

been formed as a result of being part of the group as well:

"The friendship is something else because you get in there with all the women and you joke around and that really kind 'a makes my day. Then there's times I sit by myself with you or whoever and that really means a lot to me." 


\subsubsection{Cooking}

The women reported that they enjoy the cooking part of the program. Some of the women enjoy trying new foods and learning how to prepare them. One woman said that she had never before learned how to cook. Other women commented that they already know how to cook and would prefer more sharing of diabetes information and experiences with diabetes:

"Most people know about cooking and so on... we need change; everyone in the kitchen, not really talking, just cooking, that's all."

Most of the women report using the recipes from the program and a desire for more recipes. For some, shopping for groceries now involves label reading:

"I think I've changed the way I'm eating now and I'm very... like I read the labels now on all the stuff I buy. I look for things that are good for me and I don't eat fried foods. I used to be into french fries and hash browns, the whole bit. But now I'm not eating them. I don't even look at those things when I go shopping, I just pass it by."

\subsubsection{Information and support sharing among participants}

Listening to each other's experiences with diabetes is important to the participants of Diabetes Morning. If there was a sense of not fitting in or not feeling supported, it was when the group would not respond to questions. One woman commented that she liked the fact that many of the women are Aboriginal, like herself. Many of the conversations among themselves were in their first language. While most of the women appeared confident communicating in English, translation was used during the group interview. One of the women translated several segments of the interview to a family member in the group. 
Almost everyone enjoyed listening to others share. Sometimes, the women were shy at first and wouldn't share, but got used to it:

"The first time I went, I wasn't sure what it was all about and I wasn't sure I'd enjoy myself and I was kind of apprehensive about sharing some of the stuff about my life. But after, I got used to it."

During the group interview, we became sidetracked as one of the women began to ask a few questions about diabetes symptoms to which she received uninhibited responses from the other women- evidence that sharing experiences and information works well for these women. In another interview, one woman said that she learned a lot about stroke from the other ladies who had also experienced strokes. She shared how her experience with diabetes can help others:

"When someone is diagnosed with diabetes, I can understand now how they feel because being young, I feel, to have diabetes kick in and all the problems that I've had, I can understand why they say they're afraid and it affects their life. It does, especially if you don't look after yourself. It will affect you... maybe not now but after. So you really have to be careful when you have diabetes."

Casual conversation on an individual basis was often an alternative to the larger group setting for sharing information. Whether conversations are one on one or in a group, the women share: their experiences; recipes they use; how to care for their eyes; and which health care practitioners to visit. For instance, some of the women would watch one woman who uses margarine or oil instead of lard in her bannock recipe as she would frequently prepare it for the group. In another instance, eye care discussions among the women raised one woman's level of awareness about her own deteriorating eye condition:

"...I hear some of the other ladies and some of the troubles that they have. I don't know her name but her eyesight... when my sugars were really bad, you know, sometimes even to look from here to trying to see that house over there, it's blurry." 
In an attempt to understand how to manage diabetes, the women discuss their visits with health care practitioners:

"There is a lot I don't know- like women in the group, there is a lot of thingschoosing a doctor for this- and clinic. One woman, her doctor didn't do much good for her and I started to tell her about some things that [I know]. She couldn't believe it!"

Sometimes, the information shared was not accurate. One woman commented on a conversation she had with one of the women in the group, "... she just goes by what you hear...I think I'm like that." One conflicting piece of information that most of the women picked up while sharing their experiences is information about borderline diabetes. $^{\dagger \dagger}$ The women hear that they are borderline from one health care practitioner and then hear that there is no such thing as borderline diabetes from another health care professional.

\subsubsection{Information and support sharing with staff}

The women find the staff to be supportive, providing answers to their many questions:

"I find you can ask them anything. If they can't give you the answer right away, they'll send the material to your home."

The women have found the information shared about foot care, "the poke," blood pressure checks and medication education to be beneficial. For example, one woman who felt she was taking too many different kinds of medications and was considering eliminating some of them, learned how that could be harmful, causing further complications:

\footnotetext{
${ }^{\dagger f \dagger}$ Borderline diabetes is a term that is sometimes used to explain the onset of diabetes symptoms.
} 
"When [the nurse] explained [my medications], I thought, well, I better make the effort to take my medication."

The women like the informal sharing in a group or one on one with staff as they do with fellow participants. While they note that the staff manages well with so much to do in such a short period of time, they are always busy and don't always have time to answer all the women's questions. Specifically, the women believe that having another nurse present would make a big difference. Alternately, it would be helpful if there could be more opportunities than once a month to attend an educational session and see a nurse:

"I know the cost factor might be an issue but I'd like it if we could meet weekly, then do cooking or education or sharing, something different each week. There's so many diabetics who'd like to go to something like Diabetes Morning but there's no support group for diabetics, there's not enough."

More information is needed about choosing a physician and/or clinic. The women stated on several occasions that it would be helpful to have pamphlets for themselves or to hand out to family and friends who want to know more about the program and about diabetes:

"I like the informal sharing of the group each month, being able to talk to other women with diabetes or others, at least to talk with them about it because a lot of people don't know how to control their diabetes. I also think it would help to get together pamphlets of information to pass on for those who may be afraid to reach out, to look for help."

At times, there seemed to be confusion about which health care practitioner to talk with about their different concerns. Sometimes, the participants wouldn't ask questions of the nutritionists/dieticians because they didn't think they have knowledge about anything other than nutrition in relation to diabetes.

While monetary support for babysitting and transportation was used and appreciated, it was not always the answer to being able to attend the program due to distance. Some of the women who would like to attend regularly live in a different part of the city and would like to attend something in their own community. 
There was a unanimous desire to obtain more information and more opportunities to attend programs like Diabetes Morning. Information requested is mostly in written form such as pamphlets, booklets, and recipes. Written material can be taken home and is often re-read. More recipes were also requested. The experience of Diabetes Morning, while not without its challenges, led to an expressed desire to have more programming similar to Diabetes Morning more often, in more locations within the city, and on the reserves as well. 


\section{CHAPTER FIVE}

\section{DISCUSSION AND CONCLUSION}

\subsection{Introduction}

In this chapter, the impact that Diabetes Morning had on the participants' health and well-being is highlighted from the findings, and domains for outcome indicators for the program are presented. This is followed by a discussion about living with diabetes based on the women's stories and published literature, and domains for contextual indicators. Implications for the Diabetes Moming program include suggestions for integrating domains for contextual and outcome indicators into the program. There is further discussion about the strengths and limitations of the study and suggestions for further research, followed by concluding comments.

\subsection{The Impact of Diabetes Morning on the Women's Health and Well-being}

In this section, positive impacts on the women's health and well being are presented in relation to the Diabetes Morning conceptual model and the results of the 1999 Diabetes Morning focus group. Based on the stories of the women who participated in this study, the specific objectives of Diabetes Morning are clearly being met, as are most of the expectations of the women who participated in the 1999 Diabetes Morning focus group. For many of the projected outcomes, I found evidence of program impacts. However, when the women's experiences of living with diabetes and the expectations they shared in the 1999 Diabetes Morning focus group are considered, gaps in service are 
evident: gaps in new knowledge, improved attitudes toward diabetes and its management, sufficient support from peers and health services, access to appropriate foods, and information about Diabetes Morning to share with others.

\subsubsection{Objectives of the Program}

Participants have learned about planning and preparing low-cost diabetes-friendly meals and snacks, as stated in the first objective. In alignment with the second objective, they have also gained a greater understanding of diabetes management and control through informal education sessions and discussions with diabetes educators. Meeting these objectives coincides with other outcomes. For example, they have not only "gained a greater understanding of diabetes management and control" through diabetes educators, but also through other participants in the program. They are monitoring their blood sugar and blood pressure levels as well as learning more about the medications that they are taking.

5.2.2 Projected Outcomes, 1999 Diabetes Morning focus group results ${ }^{t+t}$ and positive impacts of the program as possible outcome indicators

Projected outcomes are defined as benefits for participants during and after program activities. Considering program activities, this implies that meeting monthly to cook together, participating in informal teaching sessions, sharing with other participants, and advocacy to obtain resources necessary for diabetes management will result in

\#+ Analysis for the 1999 Diabetes Morning focus group was performed by program staff whereby results of the focus group were categorized according to the projected outcomes. These same categories are used for comparison in this section. 
benefits for the women in Diabetes Morning. Clearly, the women who shared their stories have revealed benefits they have obtained through their participation: benefits in alignment with the projected outcomes and the results of the 1999 focus group. This alignment is evidence that a difference has been made in the lives of these women due to their participation in the program. Domains for outcome indicators derived from the experiences of the participants could be used to further define the program's projected outcomes and build on the success of the program.

In the program's Performance Improvement Model, (see Table 1, pg. 10) outcome indicators are measures of the benefits obtained by program participants. ${ }^{29}$ Domains for outcome indicators could be developed into indicators to measure their frequency of occurrence (number and percent). In order to measure change over time, a baseline would need to be established. One way this could be done is by developing an intake questionnaire for new participants. This form could include closed-ended questions and open-ended questions related to the outcomes. Closed-ended questions could require a yes/no response and open-ended questions could require further explanation of the closed-ended question or information that was not captured in the questions. This same questionnaire could be revisited in 3 to 6 month intervals comparing results with previously completed questionnaires. Not only does this provide the program with information needed for program planning, it also provides the participant with information about what benefits they could potentially receive and have received over time. Table 5 shows the projected outcomes of Diabetes Morning, 1999 focus group results categorized by projected outcomes, and impacts of the program as domains for outcome indicators. 
Table 5: Diabetes Morning projected outcomes*, 1999 Focus group results of participant-identified expected outcomes and health needs*, and impacts of Diabetes Morning as domains for outcome indicators**

\begin{tabular}{|c|c|c|}
\hline $\begin{array}{l}\text { Diabetes Morning } \\
\text { projected outcomes }\end{array}$ & $\begin{array}{l}1999 \text { Focus group results: } \\
\text { Participant-identified } \\
\text { expected outcomes and health } \\
\text { needs }\end{array}$ & $\begin{array}{l}\text { Impacts of Diabetes Morning } \\
\text { as domains for } \\
\text { outcome indicators }\end{array}$ \\
\hline New knowledge & $\begin{array}{l}\text {-To learn what to eat } \\
\text {-To learn how to eat } \\
\text {-To sample new recipes } \\
\text {-Eating properly portioned foods }\end{array}$ & $\begin{array}{l}\text {-Understanding the importance of taking prescribed medication, and } \\
\text { understanding the different kinds of medications for diabetes and } \\
\text { complications } \\
\text {-Increasing awareness about diet and exercise } \\
\text {-Understanding what diabetes is about } \\
\text {-Questions answered by staff (ie: material sent to home) } \\
\text {-Learned about a variety of diabetes-friendly foods }\end{array}$ \\
\hline New skills & $\begin{array}{l}\text {-To learn what to cook } \\
\text {-Help family cook better meals } \\
\text {-Blood testing }\end{array}$ & $\begin{array}{l}\text {-Label reading } \\
\text {-Cooking diabetes-friendly meals } \\
\text {-Cooking with recipes prepared at Diabetes Morning }\end{array}$ \\
\hline Attitude & $\begin{array}{l}\text {-Take away fear, anger, why me } \\
\text { feeling } \\
\text {-Develop self confidence } \\
\text {-Feel less discouraged- its an } \\
\text { uplifting experience }\end{array}$ & $\begin{array}{l}\text {-Improved attitude about living with diabetes } \\
\text {-Moving from denial to acceptance of the disease } \\
\text {-Coming to terms with diabetes } \\
\text {-Accepting diabetes as a way of life } \\
\text {-Recommend program to others based on personal experience } \\
\text {-Understanding reason for taking prescribed medication facilitates } \\
\text { adherence to regimen } \\
\text {-Maintain positive thoughts about health } \\
\text {-Getting over shyness about sharing personal experiences } \\
\text {-Motivation to exercise (ie: doing stairs inside when too cold outside) }\end{array}$ \\
\hline
\end{tabular}

* Derived from program documentation

**Derived from the findings in the present study 


\begin{tabular}{|c|c|c|}
\hline Behaviour & $\begin{array}{l}\text {-To sample new recipes } \\
\text {-Help family cook better meals } \\
\text {-Exercise } \\
\text {-See doctor regularly } \\
\text {-Enough rest } \\
\text {-To eat } \\
\text {-Quit smoking } \\
\text {-Not use a large amount of } \\
\text { alcohol }\end{array}$ & $\begin{array}{l}\text {-Label reading when grocery shopping } \\
\text {-Monitoring blood sugar levels } \\
\text {-Taking medications as prescribed } \\
\text {-Removing foods from cupboard that are not diabetes-friendly } \\
\text {-Not purchasing foods that are not diabetes-friendly } \\
\text {-Purchasing foods in moderation results in decreased grocery costs } \\
\text {-Increased amount of exercise (ie: walking, doing stairs) }\end{array}$ \\
\hline Improved condition & & $\begin{array}{l}\text {-Lowered blood pressure and blood glucose levels } \\
\text {-Ulcers healing } \\
\text {-Weight loss }\end{array}$ \\
\hline Altered health status & -Look after your feet and eyes & $\begin{array}{l}\text {-Lowered blood pressure and blood glucose levels } \\
\text {-Ulcers healing } \\
\text {-Weight loss }\end{array}$ \\
\hline Peer support & $\begin{array}{l}\text {-To share information with } \\
\text { others } \\
\text {-Help prevent us from feeling } \\
\text { we're alone } \\
\text {-To share feelings and thoughts }\end{array}$ & $\begin{array}{l}\text {-Friends and family in program } \\
\text {-Information shared with others outside Diabetes Morning } \\
\text {-New friendships and support developed among participants and staff } \\
\text {-Information shared with/by participants and staff (ie: experiences with } \\
\text { diabetes, stroke, eyesight, choosing doctor or clinic, etc...) } \\
\text {-Translating to Cree for/by other participants } \\
\text {-One-on-one time available for sharing } \\
\text {-Group time available for sharing }\end{array}$ \\
\hline
\end{tabular}




\begin{tabular}{|c|c|c|}
\hline Values & $\begin{array}{l}\text {-Help me to know how to } \\
\text { prevent me getting diabetes }\end{array}$ & $\begin{array}{l}\text {-Strong values about prevention: desire to share knowledge and } \\
\text { resources with others to stop this epidemic affecting their lives }\end{array}$ \\
\hline Primary prevention & $\begin{array}{l}\text {-Help family cook better meals } \\
\text {-Affordable food } \\
\text {-To eat } \\
\text {-Quit smoking } \\
\text {-Not use a large amount of } \\
\text { alcohol }\end{array}$ & $\begin{array}{l}\text {-Increased awareness about diet and exercise } \\
\text {-Understanding what diabetes is about } \\
\text {-Learned about a variety of diabetes-friendly foods } \\
\text {-Label reading } \\
\text {-Cooking diabetes-friendly meals } \\
\text {-Cooking with recipes prepared at Diabetes Morning } \\
\text {-Maintain positive thoughts about health } \\
\text {-Getting over shyness about sharing personal experiences } \\
\text {-Motivation to exercise (ie: doing stairs inside when too cold outside) } \\
\text {-Removing foods from cupboard that are not diabetes-friendly } \\
\text {-Not purchasing foods that are not diabetes-friendly } \\
\text {-Purchasing foods in moderation results in decreased grocery costs } \\
\text {-Increased amount of exercise (ie: walking, doing stairs) } \\
\text {-Weight loss } \\
\text {-Strong values about prevention: desire to share knowledge and } \\
\text { resources with others to stop this epidemic affecting their lives }\end{array}$ \\
\hline Empowerment & $\begin{array}{l}\text {-Develop self confidence } \\
\text {-Feel less discouraged- its an } \\
\text { uplifting experience }\end{array}$ & $\begin{array}{l}\text {-Informal sharing of the group } \\
\text {-Information from Diabetes Morning shared with others who do not } \\
\text { attend the program }\end{array}$ \\
\hline $\begin{array}{l}\text { Ultimate goal: } \\
\text { decreased health care } \\
\text { costs through } \\
\text { improved diabetes } \\
\text { management }\end{array}$ & & -Diabetes management improved overall \\
\hline
\end{tabular}


In 1999, participants identified health needs and expected outcomes of the program related to the program's projected outcomes. In relation to the program's projected outcome called 'new knowledge', they revealed that they wanted to learn about what and how to eat including portion sizes and sampling new recipes. In this study, many women reported that they obtained new knowledge that included an increased awareness about diet but also included a range of other new knowledge. They report an increased understanding of what diabetes is about, the importance of taking prescribed medications, and the different medications taken for diabetes and its complications.

The women report developing 'new skills' in cooking diabetes-friendly meals and using recipes prepared in the program. Label reading is also a new skill for some. The 1999 focus group revealed that they would have also liked to help family cook better meals. This may or may not have occurred as it was not shared in these findings.

'Attitudes' about living with diabetes also improved. They report: moving from denial to acceptance of the disease, coming to terms with diabetes, and accepting diabetes as a way of life. Some have recommended the program to others based on their personal experiences. An understanding of the reasons for taking prescribed medication facilitated adherence to a regimen which often includes medications for complications such as stroke and high blood pressure. Other attitudes expressed include maintaining positive thoughts about health and making efforts to get over shyness about sharing personal experiences. Several women expressed a motivation to exercise (ie: doing stairs inside the apartment building when it's too cold outside).

Evidence about attitudes coincides with the projected outcome of empowerment, where the women who participated in the 1999 focus group stated that they hope to build self-confidence and feel less discouraged and more uplifted. Program documentation defines empowerment as a feeling of control over disease. The findings suggest that the 
women felt empowered through informal sharing with other participants and staff, and by the fact that they share the information they gleaned from the program with others outside the program.

The women experienced a variety of changes in behaviors that support diabetes management such as: reading labels when grocery shopping; monitoring blood sugar levels in relation to different foods they eat; taking medications as prescribed; removing foods from cupboard that are not diabetes-friendly such as oils for purposes of deepfrying; not purchasing foods that are not diabetes-friendly such as deep-fried foods; purchasing foods in moderation thereby decreasing grocery costs; and increased amounts of exercise such as walking and doing stairs. Considering the 1999 focus group results, the findings did not give any indication that they were: seeing a doctor on a regular basis; getting enough rest; had quit smoking; or whether or not they drink alcohol. However, changed behaviors indicate that diabetes management improved overall, suggesting that the ultimate goal of decreased health-care costs through improved diabetes management could be achieved.

Improved conditions and altered health status were also reported. They include: lowered blood glucose levels and blood pressure; a healing ulcer and weight loss. The 1999 focus group shows a need for looking after one's eyes and feet and staff categorized this as an indication of altered health status. The 1999 focus group results did not list expectations or needs in the improved conditions category. This could be due to the number of ideas they were limited to sharing at that time or the staff's categorization process of focus group results.

It is evident that the women found peer support in the group. As stated in the focus group results, they were hoping to share information with others in the program in an attempt to help prevent them from feeling they are alone, and to share feelings and 
thoughts. Findings show that their expectations were realized and that: support was achieved through friends and family in the program; information was shared with others outside Diabetes Morning; new friendships and support were developed among participants and staff; information was shared with/by participants and staff (ie: experiences with diabetes, stroke, eyesight, choosing doctor or clinic, etc...); translation to Cree happened among the participants; and sharing time was available as a group and one-on-one.

Strong values about prevention were expressed through a general desire to share knowledge and resources with others in order to stop this epidemic affecting their lives. In the focus group results, women expressed a desire to know how to prevent diabetes. Most of the women have been diagnosed with diabetes and still exude a strong desire for further prevention.

The list of impacts related to the program category called 'primary prevention' further supports this finding. The women report: an increased awareness about diet and exercise; an understanding of what diabetes is about; having learned about a variety of diabetes-friendly foods, label reading, cooking diabetes-friendly meals; cooking recipes at home that they helped prepare at Diabetes Morning; maintaining positive thoughts about health; getting over shyness about sharing personal experiences; motivation to exercise; removing foods from cupboard that are not diabetes-friendly; not purchasing foods that are not diabetes-friendly; purchasing foods in moderation resulting in decreased grocery costs; increased amounts of exercise; and weight loss. Only two of 1999 focus group results in this category were not captured in these findings: helping family cook better meals; and, whether or not anyone quit smoking or consumed any alcohol. While they had the opportunity to eat and take home food when they attended the program, not everyone was able to afford the appropriate foods for managing 
diabetes. Knowing how to plan and prepare appropriate foods is only useful when the foods can be purchased or obtained. While some women found they had learned to find affordable and appropriate foods when buying in moderation, others are still faced with an inability to obtain the foods they need. Thus, inappropriate foods that are easier to obtain continue to replace the diabetes-friendly foods.

Other unmet needs and/or gaps in services were identified by the women through their experiences of living with diabetes. This information could be captured in the future by including these items on the intake form. As listed below, the women's stories reveal that they:

-Distrust "those charts on the wall"

-Require a better understanding of chronic disease

-Need to know which health care practitioner to talk to about different concerns

(ie: dietitian, nutritionist, nurse, etc...)

-Fear the needle

-Go by how they feel

-Are not always taking medication as prescribed

-Need more support from health care practitioners due to shortage of staff

-Require more meeting times in order to have all their needs met

-Desire more opportunities to share experiences with others

-Would like more information in printed format (ie: pamphlets, recipes, booklets, etc...

-Desire written information about the program to pass on to others (ie: Diabetes Morning pamphlet)

-Are not always able to afford foods appropriate for diabetes management 
Information about attendance and duration of time with Diabetes Morning addressed a few of the program outputs: attendance (regular or irregular), new participants, and number of participants. The actual numbers pertain only to study participants and not the participants of Diabetes Morning as a whole. However, this information provides possible output indicators as follows:

- Attendance is indicated by the number of sessions attended per individual

- Regular or irregular attendance is indicated by the percentage of sessions attended since first visit

- New participants are indicated by the sum of first time visits per month

- Number of participants is a count of participating individuals

Women who attended most often and for the longest period of time expressed satisfaction with the program more than they did unmet needs. Those who attended least often expressed unmet needs more than they did satisfaction with the program. For example, regular attendees attribute their success to the program as well as to other approaches to self-care such as modifying their diet, increased exercise, spending time with friends and keeping busy. Independence and employment were stressed as factors influencing their ability to care for themselves.

The program met many of the women's expectations and needs as they relate to the program's projected outcomes. However, the projected outcomes did not capture many of the experiences that the women shared. The information the women shared about living with diabetes could be captured with indicators that consider contextual information about the participants, fitting the philosophy of the program about participant-centred programming. 


\subsection{Living with Diabetes}

Women from Diabetes Morning, who live with diabetes, have shared with us a fundamental relationship that exists between the context of one's life and the subsequent ability to manage this chronic illness. For them, living with diabetes involves individual experiences with diagnosis, treatment, self-management and family and community support systems. These experiences portray multiple realities: some women have had positive experiences in general, and others had both positive and negative experiences. In a few instances, the experiences presented overall challenges to managing one's health and well-being. However, in all cases, there was a desire for health and well-being for themselves as well as for their communities. This desire was often the impetus for attending the program and for sharing what they learned with others.

Community was not restricted to their Saskatoon residence. In some cases, the women who participated define community as their home reserves, not the urban setting in which they are now living. However, their stories show that they are continually building a sense of community within the urban setting with family, friends, and within programs and organizations. An example is the relationships and friendships that have been built within the Diabetes Morning program. These relationships provide the women with support in providing self-care.

Relationships can be stressful as well as supportive. The women shared the impact that diabetes and its complications are having on themselves as well as on their families and communities. Complications experienced by some of the women include failing eyesight, high blood pressure, ulcers, and stroke. These experiences have led to an inability to continue working. Thus, affording appropriate foods becomes an issue. Family and communities are also affected by the devastations associated with diabetes. 
As well, the impact of diabetes on family and community often adds stressors that impact the women's ability to manage their own health and well-being: self-care is compromised by stressors associated with caring for ailing family members and grieving the loss of family and friends. Some women report caring for family members who have been disabled due to lost limbs or stroke. Others know people in their community who have become disabled. And many have lost family members through these complications.

Burdened with diabetes and its complications, the women's stories also reveal experiences with treatment, diagnosis and self-management. The story about diabetes treatment that I heard most often from most of the women was about their fear and dislike of "the needle." These discussions often included what they perceive to be the lack of validity of "those charts on the wall" that tell them what the normal glucose levels are. Based on how they feel, they often believe that the normal range is too low for them. However, not all women expressed this concern but did state that they went through periods of denial before leaming to manage their blood sugar levels. Hickey \& Carter suggest that denial could be explained as a difficulty to accept the seriousness of the diagnosis because diabetes is often asymptomatic. ${ }^{30}$ An older woman who had suffered a stroke talked about how important it is to keep diabetes under control, even at a young age, because it eventually catches up to you if you don't. This suggests there is a need to understand diabetes as a chronic disease rather than an episodic disease. ${ }^{31}$

A better understanding of diabetes as a chronic illiness could be facilitated by health care practitioners. Koch $\& \mathrm{Kralik}^{32}$ found that patients appear to be in an ongoing transition toward living with chronic illness. The stories they heard revealed that critical turning points occur in this transitional experience. They suggested that further understanding of these critical turning points could provide the patient and the service provider with insight that could be used to enhance diabetes management. 
Based on the stories from the women in Diabetes Morning, it is possible that one of those critical tuming points revolves around denial and acceptance of diagnosis, which in turn could influence one's acceptance of the needle as well as one's overall experience with treatment. Providing support soon after diagnosis helps the individual through this tuming point. Women who were newly diagnosed when they joined the program and came to accept their diagnosis have done so with support they received in the program; support from staff and other participants. Knowing they are not alone helped them get over fears, allowing them to accept diabetes and learn to manage it. Accepting the diagnosis facilitated behaviors involving diet, exercise and blood testing practices. Macaulay, Hanusaik \& Delisle also found that patients hospitalized in an on-reserve hospital benefited from the support they received as they began to experience the various stages of grief ranging from denial to acceptance. With support, patients were motivated soon after initial diagnosis to make lifestyle changes, unlike those who had been diagnosed with diabetes for a long period of time. ${ }^{33}$ An optimistic and positive attitude can also facilitate this transition and improve treatment outcomes. ${ }^{34}$ As well, programming like Diabetes Morning could facilitate making this transition toward accepting diabetes.

Another possible critical turning point in this transition toward living with diabetes is learning to manage blood sugar levels. Snoek ${ }^{34}$ stated that strict glycemic control is a balancing act that is difficult for the majority of diabetes patients as there are a variety of factors that affect metabolic control aside from individual behavior. Yet, individuals and health care practitioners continue to focus on compliance as the factor that determines glycemic control. ${ }^{35,36}$ When strict control is adhered to, a high glycated hemoglobin reading is still possible. Strict control also increases the individual's risk of 
hypoglycemic unconsciousness, where the blood sugar levels drop too low and the person loses consciousness. ${ }^{34}$

Addressing fears and distrust may help the individual move through this critical tuming point of learning to manage blood sugar levels. Such adverse experiences or anticipated adverse experiences like loss of consciousness can develop into PIR (Psychological Insulin Resistance). ${ }^{34}$ PIR can manifest itself in the following ways: fear of injections due to pain and/or not getting the dosage right; and feeling that going on insulin means they have failed and will now be considered seriously ill. ${ }^{34}$ The stories of the women in this study also describe adverse experiences. In one case, the death of a loved one was blamed on the needle being administered in the hospital. Others talked about not trusting the dosage or the kind of medication they were prescribed and altered it based on how it made them feel, sometimes injecting more, other times injecting less.

Understanding the concept of chronic disease may help to alleviate fears and distrust. For example, the individual with diabetes may come to terms with the fact that she needs to manage the disease even in the absence of symptoms. However, simply telling an individual she has a chronic disease does not satisfy the need for information and inhibits efforts toward acceptance of diagnosis. One of the women I interviewed voiced her frustration about being told that she has a chronic disease. She said she learned about diabetes from other people because, "... It just doesn't sound right. Everything I tell [health care practitioners] is chronic, I don't know why. I just want to find out about, to see about these things." Hickey \& Carter $^{30}$ stated that cultural barriers to patient care exist and include a lack of cuiturally appropriate frames of reference to explain the concept of chronic disease. In general, they note that:

"When patients are informed that they have a problem that cannot be seen or felt, will be ongoing for years, and will require difficult behavioural and medical interventions, they have virtually no experience ... that will enable them to deal 
with this information. As such, it becomes very difficult for patients to accept the diagnosis and to take action on the recommendations provided. The diagnostic information may then be dismissed as inaccurate, irrelevant, or initating, and the patient often either exits the diabetic care system, or only peripherally participates in it." (p. 16-17)

Providing information in a way that respects cultural differences may facilitate a better understanding of diabetes in order to improve its management in day-to-day living.

A smoother transition could be facilitated by health care practitioners who collaborate with the individual in developing a treatment plan. Freeman \& Loewe ${ }^{37}$ claim that patient frustration can result from barriers in communication between the diabetes patient and the clinician. These barriers are based on who is viewed as in control of the clinical encounter. In general, the clinician focuses on scientific evidence rather than focusing on understanding how the patient perceives the disease and his/her treatment goals. This is not surprising considering health care practitioners are versed in the biomedical model to address disease. ${ }^{38}$ The resulting frustration between clinician and patient removes potential for collaboration. By focusing on the patients' awareness level and goals for treatment, a collaborative relationship between patient and clinician could develop. ${ }^{37}$ However, developing a collaborative relationship requires time to develop trust and a sense of control over the disease, time that is not available during most clinical visits. ${ }^{36}$ Programming like Diabetes Morning can continue to build on the relationship that begins within the clinical encounter.

Hunt, Valenzuela, \& Pugh $^{39}$ conducted interviews with Mexican American patients and found that if a patient evaluates his/her own treatment outcomes, the individual could improve his/her sense of how important personal behaviors are in managing the disease. In contrast, simply measuring compliance with treatment may not be as effective an evaluation of how well patients manage diabetes. Callaghan $\&$ Williams ${ }^{40}$ discuss the need to understand the process of living with diabetes. An 
understanding of the experiences of those who live with the disease is crucial for those who provide care. Snoek ${ }^{34}$ reflected the voice of these authors and the women in this study when he wrote:

"Diabetes is a largely self-managed condition, and without the active participation of the person with diabetes, good outcomes are difficult if not impossible to achieve. Simply blaming the poorly-controlled patient for 'not being motivated,' however, is neither realistic nor productive. Health care professionals can make an important contribution by helping patients attain better medical and psychological outcomes, but must therefore learn to understand and address the individual difficulties people with diabetes face in their daily lives. Diabetes care is not just about laboratory measures and telling the patient what he or she should or should not do. It is about teamwork, in which patients, their families and friends, and health care providers work together to optimize treatment outcomes." (p. 129)

Understanding and facilitating the transition toward living with diabetes could be built into Diabetes Morning by considering the context of the lives of the participants. Koch, Kralik \& Sonnack ${ }^{41}$ also interviewed women with diabetes who shared their stories of living with the disease. Their goal was to learn from these experiences and act on what they leamed. They believed that the women's stories could strongly impact service delivery. The stories of the women in this study also reveal information that could impact the Diabetes Morning program and programs like it. Treatment strategies should include more than individual accountability and encompass the influence of day-to-day experiences of living with diabetes. These daily experiences include family, community and regional level factors that often challenge as well as facilitate management strategies. $^{30}$ 


\subsubsection{Domains for Contextual Indicators}

Like the domains for outcome indicators directly related to the program, domains for indicators of those day-to-day experiences of living with diabetes could be used to provide baseline contextual information about the program participants and some of them could be monitored for change. Contextual indicators for living with diabetes could provide the health care practitioner with a better understanding of these experiences. This understanding could facilitate a collaborative relationship between the practitioner and the individual, involving the individual in her own treatment plan.

The term "contextual indicators" is not widely used in the literature. An extensive search of Medline, Eric and Psychinfo between 1967 to the present provided a list of 9 articles. Seven of these publications refer to primary schools as the context for which contextual indicators are developed. In one of these cases, contextual indicators were defined as criteria for improvement and were derived from qualitative research. ${ }^{42}$ The most recent use of the term was found in a 1996 publication about burglary victimization. ${ }^{43}$ Contextual indicators were based on "ambient risk" or risk factors surrounding the individual. Rountree \& Land were interested in exploring ambient risk in relation to perception of risk of burglary. The only paper found through Medline search was published in 1981 about factors pertaining to the institutionalization of welfare recipients. ${ }^{44}$ Contextual indicators were developed based on day-to-day living activities and characteristics of the target population. In general, contextual indicators were used in an attempt to inform policy and program delivery by addressing risk factors affecting the day-to-day lives of the target population. 
Five categories were derived from the experiences of the women in this study related to living with diabetes and domains for contextual indicators for living with diabetes are suggested in relation to these categories (see Table 6).

Table 6: Domains for contextual indicators for living with diabetes

\begin{tabular}{|c|c|}
\hline $\begin{array}{c}\text { Experiences } \\
\text { living with diabetes }\end{array}$ & $\begin{array}{l}\text { Domains for contextual indicators } \\
\text { for living with diabetes }\end{array}$ \\
\hline $\begin{array}{l}\text { Desire for health and } \\
\text { well-being on the } \\
\text { level of community } \\
\text { and individual }\end{array}$ & $\begin{array}{ll}- & \text { Desire for change } \\
- & \text { Reason for making change } \\
- & \text { Reason for attending the program }\end{array}$ \\
\hline $\begin{array}{l}\text { Experiences with } \\
\text { family/community } \\
\text { support }\end{array}$ & $\begin{array}{l}\text { - Identified community } \\
\text { - Available translation into first language } \\
\text { - Sufficiency of support where: } \\
\text { O What it is like to live with diabetes is understood } \\
\text { O The needs of an individual with diabetes are } \\
\text { understood } \\
\text { - Conditions of life such as: } \\
\text {. Supportive relationships (ie: family, friends, } \\
\text { programs, groups, professionals, etc...) } \\
\text { Amount of care giving and type of care given } \\
\circ \text { Ability to afford appropriate foods } \\
\circ \text { Where foods are obtained (ie: grocery, family, Food } \\
\text { Bank, etc...) } \\
\text { O Stressors (ie: worries, fears) }\end{array}$ \\
\hline $\begin{array}{l}\text { Experiences with } \\
\text { diagnosis }\end{array}$ & $\begin{array}{ll}- & \text { Age } \\
\text { - } & \text { Time since diagnosis } \\
\text { - } & \text { Family history of diabetes } \\
\text { - } & \text { Presence of other illness/disease such as complications of } \\
\text { diabetes } & \\
\text { - } & \text { Understanding of what diabetes is as a chronic disease } \\
\text { - } & \text { Understanding of the complications of diabetes (ie: ulcers, } \\
\text { foot problems, eyesight, heart disease, high blood pressure, } \\
\text { high blood cholesterol, stroke, TIA, kidney problems, etc...) } \\
\text { - Experiences with denial and acceptance of diabetes }\end{array}$ \\
\hline $\begin{array}{l}\text { Experiences with } \\
\text { treatment }\end{array}$ & $\begin{array}{l}\text { - Identify fears } \\
\text { - Identify personal family physician } \\
\text { - Identify other health care practitioners (ie: nurse, dietician, } \\
\text { alternative/traditional methods) } \\
\text { - Understanding of why medications are being prescribed, } \\
\text { how they work and the importance of taking them } \\
\text { - Understanding tests such as the finger poke and glycated } \\
\text { hemoglobin }\end{array}$ \\
\hline
\end{tabular}




\begin{tabular}{|c|c|}
\hline \multirow{4}{*}{$\begin{array}{l}\text { Experiences with } \\
\text { self-management } \\
\text { - } \quad \text { Self- } \\
\text { management } \\
\text { includes key } \\
\text { experiences with } \\
\text { treatment: } \\
\text { monitoring blood } \\
\text { sugar; diet; } \\
\text { learning from } \\
\text { others; and self- } \\
\text { care strategies }\end{array}$} & $\begin{array}{ll} & \text { Monitoring blood glucose levels } \\
\text { - } & \text { How } \\
\text { - } & \text { How often } \\
\text { - } & \text { What method } \\
\text { - } & \text { Understanding of normal range } \\
\text { - } & \text { Perceived normal range }\end{array}$ \\
\hline & $\begin{array}{ll} & \text { Diet } \\
\text { - } & \text { Patterns of eating } \\
- & \text { Foods eaten } \\
- & \text { Understanding of diabetes-friendly eating behaviours }\end{array}$ \\
\hline & $\begin{array}{l}\text { Learning from others } \\
\text { - Where has the individual learned about diabetes and how to } \\
\text { manage it (ie: others with diabetes, family, friends, health } \\
\text { care practitioners such as doctor, nurse, dietician, radio or } \\
\text { television, etc...) }\end{array}$ \\
\hline & $\begin{aligned} & \text { Self-care strategies } \\
\text { - } & \text { How challenging situations are dealt with } \\
\text { - } & \text { How diet has been modified } \\
\text { - } & \text { Exercise undertaken } \\
\text { - } & \text { Smoking status } \\
\text { - } & \text { Consumption of alcohol } \\
- & \text { Employment } \\
- & \text { Fulfilling activities undertaken day-to-day } \\
\text { - } & \text { Time spent with friends/family }\end{aligned}$ \\
\hline
\end{tabular}

In the first category, the desire for health and well-being on the level of community and individual was often the impetus behind attendance and sharing knowledge with others. Incorporating participants' desires into program objectives could facilitate participation. Domains for contextual indicators include identifying the individual's desire for change such as her reasons for making change and attending the program.

In the second category, experiences with family/community support, many of the women identified their community as their home reserve. However, they also expressed a sense of community within the urban setting where they are now living. They found support in communicating in their first language and have shared their experiences with diabetes and its complications with others. Examples of these experiences include care 
giving and grieving. Domains for contextual indicators include identifying: the individual's community as they perceive it; need and availability of translation into first language; sufficiency of support where the needs and experiences of an individual with diabetes are understood; conditions of life such as supportive relationships (ie: family, friends, programs, groups, professionals, etc...); amount of care giving and type of care given; ability to afford appropriate foods; where foods are obtained (ie: grocery, family, Food Bank, etc...); and stressors (ie: worries, fears).

With respect to experiences with diagnosis, women report experiencing denial and an eventual acceptance of the disease. They experienced a transition to living with disease, and in some cases, still struggle with knowing what is meant by the term chronic. Domains for contextual indicators include identifying: age; time since diagnosis; family history of diabetes; presence of other illness/disease such as complications of diabetes; their understanding of what chronic disease is; their understanding of the complications of diabetes (ie: ulcers, foot problems, eyesight, heart disease, high blood pressure, high blood cholesterol, stroke, TIA, kidney problems, etc...); and experiences with denial and acceptance of diabetes.

In the fourth category, experiences with treatment, the women shared a fear of the needle. Some of them don't trust charts with the standard blood sugar range. This interferes with adherence to treatment, as denial does for some women. One woman reported that she realized that non-adherence "catches up to you." Barriers between patient/health care practitioner communication also exist. A collaborative team effort between the individual and the health care practitioner would provide a stronger support system; this team effort would help practitioners who do not understand experiences of living with diabetes to better understand this context. Domains for contextual indicators include identifying: fears; a personal family physician; other health care practitioners 
seen (ie: nurse, dietician, alternative/traditional methods); whether or not the individual understands why medications are being prescribed, how they work and the importance of taking them; whether or not the individual understands tests such as the finger poke and glycated hemoglobin; and the overall importance of treatment.

The fifth and final category, experiences with self-management, is also affected by the transition toward accepting diabetes. For instance, knowing what to do does not always translate into behavior change. Thus, a barrier to diabetes management remains. Benefits to self-management include maintaining an optimistic attitude and access to support systems whereas adverse experiences can hinder self-management efforts. Self-management includes key experiences with treatment, monitoring blood sugar, diet, leaming from others and self-care strategies. Domains for contextual indicators for monitoring blood glucose levels include identifying: how the individual performs this task; how often; what method is used; whether or not the individual understands the normal range; and their perceived normal range. Domains for contextual indicators for diet include identifying: patterns of eating; foods eaten (diabetes-friendly or not); and whether or not the individual understands diabetes-friendly eating behaviors. Domains for contextual indicators for learning from others include identifying: where the individual has learned about diabetes, and how to manage it (ie: others with diabetes, family, friends, health care practitioners such as doctor, nurse, dietician, radio or television, etc...). Domains for contextual indicators for self-care strategies include identifying: how the individual deals with challenging situations; how they have modified their diet in the past and recently; if exercise is undertaken; smoking status; consumption of alcohol status; employment status; fulfilling activities undertaken day-to-day; and time spent with friends/family. 


\subsection{Implications of the Findings}

The stories shared by the women in this study can be used to inform the Diabetes Moming program. The program is built on a performance improvement model with outcomes defined as benefits to the people. The program can improve its benefits to the people by incorporating domains for outcome indicators and contextual indicators that have been derived from its participants. Rich with their experiences from living with diabetes, these domains move beyond the benefits they received from the program. They capture the women's strengths and challenges evident in their stories.

Incorporating these domains into program activities requires increased resources to fill gaps in service. Presently, three staff personnel are stretched trying to address the needs of the participants. While participants are happy with a three-hour timeframe, meeting once a month does not allow enough time for staff to provide enough support and information. Weekly meetings could increase the amount of support available from staff and other participants. More time would be available to address questions and improve self-management skills. If the programs ran more often, different days could be dedicated to cooking, education, clinics and support/sharing instead of trying to cover all areas in one meeting. It is possible that more men would attend the program or a program could be geared toward men's needs taking their context into account. Also, more locations for the program would decrease travel time for those who do not live near the West Side Community Clinic.

Incorporating the many domains for contextual and outcome indicators could be intimidating for participants and overburdening for staff. However, an integrated approach using several strategies may be a practical way to avoid overwhelming the individual or staff. Suggested strategies to integrate these domains in program activities 
include: modifying the program forms (see Appendix A and B) and combining their use with individual counseling sessions; incorporating domains into group discussions; building domains into program curriculum; and collaborating with other health care practitioners to incorporate the context of the women's lives into practice. Forms could be modified to include the domains. These forms could be used to collect baseline information about the individual, and many of these domains could be followed over time. Follow-up could occur through individual counseling every 3-6 months as well as in group discussions. Curriculum could be further developed to enhance selfmanagement skills on a daily basis. Collaboration between the individual and other health care practitioners could facilitate the individual's involvement in her treatment plan.

The women may be encouraged by a treatment plan they helped to establish in consultation with the health care practitioner who uses contextual information like the domains on the modified form. Thus, the individual becomes part of the program process, establishing a sense of ownership and encouraging adherence to the plan. Using a baseline form or questionnaire and revisiting it every 3 to 6 months serves to measure program performance and enhance skills in goal-setting. Goal-setting skills could enhance the individual's ability to integrate treatment and self-management of diabetes into their everyday life.

Hickey and Carter $^{30}$ made recommendations about how to approach cultural barriers to patient care that could also be considered by the program. They include: cross-cultural orientation for service providers; teaching skills in patient education to service providers; changing the clinic "culture" to emphasize prevention and chronic disease care; consistency and continuity of care; a team approach representing a crosssection of service providers; fast, friendly and frequent service; community outreach; and 
prevention. West Side Community Clinic already uses many of these approaches to patient care.

The women also expressed a desire for printed materials about Diabetes Morning that they could share with others. This could include some education about symptoms and complications of diabetes in Cree and French as well as English ${ }^{\S \S}$. Some examples of culturally appropriate information have been published. Hagey ${ }^{45}$ looked at metaphor surrounding diabetes and constructed meanings to explain this phenomenon. In essence, she claimed that our belief systems provide the explanations for our realities. In this case, teachings specific to Ojibway culture were narrated through the legends of Nanabush. Nanabush and the Pale Stranger is a narrative created by Aboriginal leaders and a nurse anthropologist in an attempt to provide knowledge about diabetes using a culturally acceptable vehicle. In the narrative, diabetes has a voice and talks with Nanabush and whatever Nanabush claims that diabetes has said is perceived to be true. In another study, Garrow ${ }^{31}$ used cultural terms to develop a cultural model for high blood pressure. High blood pressure was translated to mean "blood that rises" resulting from a state of imbalance. In essence, when imbalance is corrected, symptoms lessen or disappear. Similar cultural adaptations could be used to address diabetes.

\$§ Cree, French and English are the only languages I identified as first languages through conversations with participants. There may be others to consider. 


\subsection{Strengths and Limitations of the Study}

Strengths of the study include:

- Qualitative methodology supported the ability to learn about the multiple realities of the women in Diabetes Morning and reflects the heterogeneity among Aboriginal people.

- The women shared information about the context of their lives that influence their health and well-being outside the auspices of the program they are attending.

- The study participants included women who attended regularly as well as those who only attended occasionally or discontinued attendance.

- Their stories reflect similar phenomena described by others with diabetes in different contexts as outlined in the literature cited in this study.

The study also had its limitations:

- The women who participated in the group interview did share that they "can't tell [me] everything at once." Meeting as a group more than once could have revealed information otherwise missed. It would be difficult to gather the same individuals together on more than one occasion. However, more women may have had an opportunity to share their stories.

- A Cree translator helping to conduct the interviews may have also facilitated gleaning more information from some of the participants. 


\subsection{Further Research}

The next step in research would be to move from the identification of domains for contextual and outcome indicators to the creation of measurable indicators. Measurable indicators can help program planners to measure changes associated with program intervention and improve the program's performance to provide the best possible programming.

The women's stories suggest there is a need for more programming like Diabetes Morning. Based on the information that the women have shared, a needs assessment tool using outcome indicators and contextual indicators could facilitate incorporating the needs of those who are living with diabetes into diabetes education programs. This information, if obtained from program participants, would be useful in identifying gaps and unmet needs on an ongoing basis.

The needs assessment tool would also be useful in developing a chronic disease model of the transition toward living with diabetes. We need to learn more about the transition toward living with diabetes to support treatment efforts. For example, more information is needed about how to make the transition from knowing how to manage diabetes to integrating this knowledge into everyday life. Another example is the transition period between denial and acceptance of the diagnosis of diabetes. We could learn from knowing more about how health care practitioners facilitate the acceptance of diagnosis. 


\subsection{Conclusion}

Whole people enter programs, bringing with them their desires and capacities that could potentially impact and be impacted by the program that they enter. The women's stories from Diabetes Morning support this notion. Not only did Diabetes Morning impact their health and well-being; their involvement also impacted the program outcomes.

Programming like Diabetes Morning provides a unique combination of resources for people living with diabetes. It provides knowledge and support. Knowledge is obtained through experiential learning as well as the written word and a combination of oral and visual presentations of information. Support is also shared among participants who are experts in the experience of living with diabetes.

Program activities build on and sometimes create sustainable support networks for managing diabetes through relationships with family and friends. These activities also complement clinical support in managing the disease. The dietician/nutritionists and nurse who facilitate Diabetes Morning activities have provided desired and pertinent information ranging from learning to monitor blood glucose levels to informed dietary and exercise recommendations. Yet, one program that runs once per month can barely scratch the surface of need for its resources. Let it be noted that the scratch it has made is a significant one in the lives of the women whose health and well-being have benefited from its existence.

While the program has brought benefits to the people, program performance could be improved by incorporating experiences of living with diabetes into program activities. A better understanding of these experiences could enhance the program's ability to address the complexities associated with living with a chronic disease like diabetes. 


\section{REFERENCES}

1. Young TK. Chapter 1: Introduction. In Population health: concepts and methods. New York, NY: Oxford University Press, 1998:1-22.

2. Health Canada. Diabetes in Canada: National statistics and opportunities for improved surveillance, prevention, and control. Ottawa: Minister of Public Works and Government Services Canada, 1999.

3. Saskatchewan Health. Diabetes 2000: Recommendations for a strategy on diabetes prevention and control in Saskatchewan. Regina, SK: Report of the Saskatchewan Advisory Committee on Diabetes, 2000.

4. Young TK. Chapter 3: Measuring health and disease in populations. In Population health: concepts and methods. New York, NY: Oxford University Press, 1998:59-94.

5. World Health Organization, Department of Noncommunicable Disease Surveillance. Definition, diagnosis and classification of diabetes mellitus and its complications: Part 1-Diagnosis and classification of diabetes mellitus. Geneva, Switzerland: WHO, 1999.

6. Health Canada. Toward a healthy future: second report on the health of Canadians. Charlottetown, P.E.I.: Federal, Provincial and Territorial Advisory Committee on Population Health, 1999. 
7. Bobet E. Diabetes among First Nations People. Ottawa: Health Canada, 2000.

8. Canadian Institute for Child Health. Saskatchewan: The Health of Canada's Children. A CICH Profile: A Perspective on Saskatchewan. Ottawa: CIHI, 2000.

9. Daniel M \& Gamble D. Diabetes and Canada's aboriginal peoples: the need for primary prevention. Int. J. Nurs. Stud., 1995; 32(3):243-259.

10. Macaulay AC, Paradis G, Potvin L, Cross EJ, Saad-Haddad C, McComber A, Desrosiers S, Kirby R, Montour LT, Lamping DL, Leduc N, Rivard M. The Kahnawake schools diabetes prevention project: intervention, evaluation, and baseline results of a diabetes primary prevention program with a native community in Canada. Prev. Med., 1997 Nov-Dec; 26(6):779-90.

11. Waldram JB, Herring DA \& Young TK. Chapter 4: New epidemics in the twentieth century. In Aboriginal health in Canada: Historical, caltiral, and epidemiological perspectives. Toronto, ON: University of Toronto Press, 1995:65-96.

12. Saskatchewan Women's Secretariat. Profile of Aboriginal Women in Saskatchewan. Regina, SK: Saskatchewan Women's Secretariat, 1999.

13. Bachiu L, Bailey M, Dixon D, Hill A, Kornder N, Keegan C \& Matiko M. Looking after diabetes: Northern Saskatchewan Diabetes Education Programs. Saskatoon, SK: Saskatoon Tri-Hospital Diabetes Education Centre, 1998. 
14. Gittelsohn J, Harris SB, Burris KL, Kakegamic L, Landman LT, Sharma A, Wolever TMS, Logan A, Bañie A \& Zinman B. Use of ethnographic methods for applied research on diabetes among Ojibway-Cree in Northern Ontario. Health Education Quarterly, 1996; 23(3):365-382.

15. Macaulay A., Dearhouse, Chief. Successful participatory research in diabetes prevention with community researchers. Presented at National Aboriginal Diabetes Association $1^{\text {st }}$ National Conference, Winnipeg, Manitoba, 2000.

16. Saskatchewan Health. Population Health Promotion Demonstration Projects for the Primary Prevention of Diabetes. Regina, SK: Saskatchewan Health, 1999.

17. Shah CP. Chapter 1: Concepts, determinants and promotion of health. In Public Health and Preventive Medicine in Canada. $4^{\text {th }}$ Ed. University of Toronto Press: Toronto, 1998:1-28.

18. Young TK. Chapter 7: Planning population health interventions. In Population health: concepts and methods. New York, NY: Oxford University Press, 1998:210237.

19. Whiting, JA, Waldram, JB, Habbick, BF, \& Kornder, NM. A Diabetes education program for irban dwelling Aboriginal people. Saskatoon, SK: Saskatoon District Health, 1998. 
20. United Way Of America: Outcome Measurement Resource Network. Measuring Program Outcomes: A Practical Approach. Available at:

http://national.unitedway.org. Accessed on February 22, 1999.

21. United Way. Program Outcome Model. Available at: http://national.unitedway.org/outcomes/model.htm. Accessed on February 22, 1999.

22. Lincoln Y.S. \& Guba E. Naturalistic Inquiry. Beverly Hills, CA: Sage, 1985

23. Leininger M. Evaluation criteria and critique of qualitative research studies. In J.M Morse (Ed.), Critical Issties in Qualitative Research Methods. Thousand Oaks, CA: Sage, 1994:95-115.

24. Sword, W. Accounting for the presence of self: Reflections on doing qualitative research. Qualitative Health Research, 1999; 9(2):270-278.

25. World Health Organization. Health Promotion Evaluation: Recommendations to Policy Makers: Report of the WHO European Working Group on Health Promotion Evaluation. Geneva: WHO in collaboration with Health Canada, Centers for Disease Control and Prevention, United States and Health Education Authority, United Kingdom, 1998.

26. Deiter C \& Otway L. Research as a spiritual contract: an Aboriginal women's health project. Centres of Excellence for Women's Health Research Bulletin. Winter 2002; 2(3):14-15. 
27. Bopp J, Bopp M, Brown L \& Lane Jr P, producers. The Sacred Tree: Reflections on Native American Spirituality. Third Edition: Twin Lakes, WI: Lotus Light Publications, 1989.

28. Berkow R \& Talbott JH, editors. The Merck Manual of Diagnosis and Therapy. Thirteenth Edition: Whitehouse Station, NJ, USA: Merck \& Co., Inc., 1977.

29. United Way Of America. Outcome Measurement Resource Network. Why measure outcomes? In Measuring Program Outcomes: A Practical Approach. Available at: http:/national.unitedway org/outcomes/why.htm. Accessed in 1996.

30. Hickey ME \& Carter JS. Cultural barriers to delivering health care: The non-Indian provider perspective. IN: Joe JR \& Young RS, editors. Diabetes as a disease of civilization: the impact of cultural change on indigenous peoples. Berlin and New York: Mouton de Gruyter, 1993:453-470.

31. Garro LC. Explaining high blood pressure: variation in knowledge about illness. American Ethriologist. 1988; 15:98-119.

32. Koch T \& Kralik D. Chronic illness: reflections on a community-based action research programme. Joumal of Advanced Nursing. 2001; 36(1):23-31.

33. Macaulay AC, Hanusaik $N, \&$ Delisle DD. Diabetic education program in the Mohawk community of Kahnawake, Quebec. Can. Fam. Physician. 1988; July, 34:1591-93. 
34. Snoek FJ. Breaking the barriers to optimal glycaemic control — what physicians need to know from patients' perspectives. Int J Clini Pract Sinppl. 2002; Jul, 129:80-84.

35. Abonyi S. Sickness and Symptom among the Mushkegowuk Cree: Perspectives on Diabetes [dissertation]. Hamilton, ON: McMaster University, Department of Anthropology, 2001.

36. Hanson RW. Physican-patient communication and compliance. Gerber KE \& Nehemkis AM, Eds. In Compliance: The dilemma of the chronically ill. New York, NY; Springer Publishing Company, 1986:182-212.

37. Freeman J \& Loewe R. Barriers to communication about diabetes mellitus: patients' and physicians' different views of the disease. The Joumal of Family Practice. 2000 Jun;49(6):507-12.

38. O'Neil JD. Colonial stress in the Canadian Artic: An ethnography of young adults changing. Janes CR, Stall R, Gifford SM, Eds. In Anthropology and Epidemiology, Dordrecht, Holland: D. Reidel Publishing Company, 1986:213-246.

39. Hunt LM, Valenzuela MA \& Pugh JA. Porque me tocó a mi ? Mexican American diabetes patients' causal stories and their relationship to treatment behaviors. Soc. Sci. Med. $1998 ; 46(8): 959-969$.

40. Callaghan D \& Williams A. Living with diabetes: issues for nursing practice. Journal of Advanced Nursing. 1994; 20:132-139. 
41. Koch T, Kralik D \& Sonnack D. Women living with type II diabetes: the intrusion of ilness. Joumal of Clinical Nirsing. 1999; 8:712-722.

42. Jolly DV, et al. Developing effective schools: indicators of educational success as roadmarks to improvement. Paper presented at the Annual Meeting of the American Educational Research Association, Boston MA, April 16-20, 1990.

43. Rountree PW, \& Land KC. Burglary victimizatroin, perceptions of crime risk, and routine activities: a multilevel analysis across Seattle neighborhoods and census tracts. Journal of Research in Crime and Delinquency, 1996; May, 33(2):147-80.

44. McCoy JL \& Edwards BE. Contextual and sociodemographic antecedents of institutionalization among aged welfare recipients. Med. Care. 1981; Sept, 19(9):90721.

45. Hagey R. The phenomenon, the explanations and the responses: metaphors surrounding diabetes in urban Canadian Indians. Soc. Sci. Med.. 1984; 18(3):265-272. 


\section{BIBLIOGRAPHY}

Abonyi S. Sickness and Symptom among the Mushkegownk Cree: Perspectives on Diabetes [dissertation]. Hamilton, ON: McMaster University, Department of Anthropology, 2001.

Bachiu L, Bailey M, Dixon D, Hill A, Kornder N, Keegan C \& Matiko M. Looking after diabetes: Northem Saskatchewan Diabetes Edacation Programs. Saskatoon, SK: Saskatoon Tri-Hospital Diabetes Education Centre, 1998.

Berkow R \& Talbott JH, editors. The Merck Mamual of Diagnosis and Therapy. Thitteenth Edition: Whitehouse Station, NJ, USA: Merck \& Co., Inc., 1977.

Bobet E. Diabetes among First Nations People. Ottawa: Health Canada, 2000.

Bopp J, Bopp M, Brown L \& Lane Jr P, producers. The Sacred Tree: Reflections on Native American Spininality. Third Edition: Twin Lakes, WI: Lotus Light Publications, 1989.

Callaghan D \& Williams A. Living with diabetes: issues for nursing practice. Journal of Advanced Nursing. 1994; 20:132-139.

Canadian Institute for Child Health. Saskatchewan: The Health of Canada's Children. A CICH Profile: A Perspective on Saskatchewañ. Ottawa: CHI, 2000. 
Daniel M \& Gamble D. Diabetes and Canada's aboriginal peoples: the need for primary prevention. Int. J. Nurs. Stud., 1995; 32(3):243-259.

Deiter C \& Otway L. Research as a spiritual contract: an Aboriginal women's health project. Centres of Excellence for Women's Health Research Bulletin. Winter 2002; 2(3):14-15.

Freeman J \& Loewe R. Barriers to communication about diabetes mellitus: patients and physicians' different views of the disease. The Journal of Family Practice. 2000 Jun;49(6):507-12.

Garro LC. Explaining high blood pressure: variation in knowledge about illness. American Ethnologist. 1988; 15:98-119.

Garro LC. Individual or societal responsibility? Explanations of diabetes in an Anishinaabe (Ojibway) Community. Soc. Sci.Med. 1994; 40, 1:37-46.

Gittelsohn J, Harris SB, Burris KL, Kakegamic L, Landman LT, Sharma A, Wolever TMS, Logan A, Barnie A \& Zinman B. Use of ethnographic methods for applied research on diabetes among Ojibway-Cree in Northern Ontario. Health Education Quarterly, $1996 ; 23(3) ; 365-382$

Hagey $\mathrm{R}$. The phenomenon, the explanations and the responses: metaphors surrounding diabetes in urban Canadian Indians. Soc. Sci. Med.. 1984; 18(3):265-272. 
Hanson RW. Physican-patient communication and compliance. Gerber KE \& Nehemkis AM, Eds. In Compliance: The dilemma of the chronically ill. New York, NY; Springer Publishing Company, 1986:182-212.

Health Canada. Diabetes in Canada: National statistics and opportunities for improved surveillance, prevention, and control. Ottawa: Minister of Public Works and Government Services Canada, 1999.

Health Canada. Toward a healthy future: second report on the health of Canadians. Charlottetown, P.E.I: Federal, Provincial and Territorial Advisory Committee on Population Health, 1999.

Hickey ME \& Carter JS. Cultural barriers to delivering health care: The non-Indian provider perspective. IN: Joe JR \& Young RS, editors. Diabetes as a disease of civilization: the impact of cultural change on indigenous peoples. Berlin and New York: Nouton de Gruyter, 1993:453-470.

Hunt LM, Valenzuela MA \& Pugh JA. Porque me tocó a mi ? Mexican American diabetes patients' causal stories and their relationship to treatment behaviors. Soc. Sci. Med. 1998; 46(8):959-969.

Jolly DV, et al. Developing effective schools: indicators of educational success as roadmarks to improvement. Paper presented at the Annual Meeting of the American Educational Research Association, Boston MA, April 16-20, 1990. 
Koch T \& Kralik D. Chronic illness: reflections on a community-based action research programme. Journal of Advanced Nursing. 2001; 36(1):23-31.

Koch T, Kralik D \& Sonnack D. Women living with type II diabetes: the intrusion of illness. Journal of Clinical Nursing. 1999; 8:712-722.

Leininger M. Evaluation criteria and critique of qualitative research studies. In J.M Morse (Ed.), Critical Issues in Qualitative Research Methods. Thousand Oaks, CA: Sage, 1994:95-115.

Lincoln Y.S. \& Guba E. Naturalistic Inquiry. Beverly Hills, CA: Sage, 1985

Macaulay A., Dearhouse, Chief. Successful participatory research in diabetes prevention with community researchers. Presented at National Aboriginal Diabetes Association $1^{\text {st }}$ National Conference, Winnipeg, Manitoba, 2000.

Macaulay AC, Hanusaik N, \& Delisle DD. Diabetic education program in the Mohawk community of Kahnawake, Quebec. Can. Fam. Physician. 1988; July, 34:1591-93.

Macaulay AC, Paradis G, Potvin L, Cross EJ, Saad-Haddad C, McComber A, Desrosiers S, Kirby R, Montour LT, Lamping DL, Leduc N, Rivard M. The Kahnawake schools diabetes prevention project: intervention, evaluation, and baseline results of a diabetes primary prevention program with a native community in Canada. Prev. Med., 1997 NovDec; 26(6):779-90. 
McCoy JL \& Edwards BE. Contextual and sociodemographic antecedents of institutionalization among aged welfare recipients. Med. Care. 1981; Sept, 19(9):907-21.

O'Neil JD. Colonial stress in the Canadian Artic: An ethnography of young adults changing. Janes CR, Stall R, Gifford SM, Eds. In Anthropology and Epidemiology, Dordrecht, Holland: D. Reidel Publishing Company, 1986:213-246.

Rountree PW, \& Land KC. Burglary victimizatroin, perceptions of crime risk, and routine activities: a multilevel analysis across Seattle neighborhoods and census tracts. Journal of Research in Crime and Delinquency, 1996; May, 33(2):147-80.

Saskatchewan Health. Diabetes 2000: Recommendations for a strategy on diabetes prevention and control in Saskatchewan. Regina, SK: Report of the Saskatchewan Advisory Committee on Diabetes, 2000.

Saskatchewan Health. Population Health Promotion Demonstration Projects for the Primary Prevention of Diabetes. Regina, SK: Saskatchewan Health, 1999.

Saskatchewan Women's Secretariat. Profile of Aboriginal Women in Saskatchewan. Regina, SK: Saskatchewan Women's Secretariat, 1999.

Shah CP. Chapter 1: Concepts, determinants and promotion of health. In Public Health and Preventive Medicine in Canada. $4^{\text {th }}$ Ed. University of Toronto Press: Toronto, 1998:1-28. 
Snoek FJ. Breaking the barriers to optimal glycaemic control-what physicians need to know from patients' perspectives. Int J Clin Pract Suppl. 2002; Jul, 129:80-84.

Sword, W. Accounting for the presence of self: Reflections on doing qualitative research. Qualitative Health Research. 1999; 9(2):270-278.

Thompson SJ \& Gifford SM. Trying to keep a balance: the meaning of health and diabetes in an urban Aboriginal community. Social Science \& Medicine. 2000; 51:14571472.

United Way Of America. Outcome Measurement Resource Network. Measuring Program Outcomes: A Practical Approach. Available at: http://national unitedway.org. Accessed on February 22, 1999.

United Way. Program Outcome Model. Available at: http://national.unitedway org/outcomes/model.htm. Accessed on February 22, 1999.

United Way Of America. Outcome Measurement Resource Network. Why measure outcomes? In Measuring Program Outcomes: A Practical Approach. Available at: http:/national.unitedway org/outcomes/why.htm. Accessed on February 22, 1999.

Waldram JB, Herring DA \& Young TK. Chapter 4: New epidemics in the twentieth century. In Aboriginal health in Canada: Historical, cultural, and epidemiological perspectives. Toronto, ON: University of Toronto Press, 1995:65-96. 
Whiting, JA, Waldram, JB, Habbick, BF, \& Kornder, NM. A Diabetes education program for urban dwelling Aboriginal people. Saskatoon, SK: Saskatoon District Health, 1998.

World Health Organization, Department of Noncommunicable Disease Surveillance. Definition, diagnosis and classification of diabetes mellitus and its complications: Part 1Diagnosis and classification of diabetes mellitus. Geneva, Switzerland: WHO, 1999.

World Health Organization. Health Promotion Evaluation: Recommendations to Policy Makers: Report of the WHO European Working Group on Health Promotion Evaluation. Geneva: WHO in collaboration with Health Canada, Centers for Disease Control and Prevention, United States and Health Education Authority, United Kingdom, 1998.

Young TK. Chapter 1: Introduction. In Population health: concepts and methods. New York, NY: Oxford University Press, 1998:1-22.

Young TK. Chapter 3: Measuring health and disease in populations. In Population health: concepts and methods. New York, NY: Oxford University Press, 1998:59-94.

Young TK. Chapter 7: Planning population health interventions. In Population health: concepts and methods. New York, NY: Oxford University Press, 1998:210-237. 


\section{APPENDIX A}

Diabetes Morning General and Medical Information (two pages)

Date:

Name:

Address:

Hypertension

Altered lipids

Other Health Problems

Mobility Difficulties

Limits to Exercise

Attended Foot Care Session

Meter

Advocacy for Meter

Advocacy for increase in SAP

Need transportation

Need child care

Brings family member
Physician \&

Address:
No

Yes

๖

$\square \quad \square$
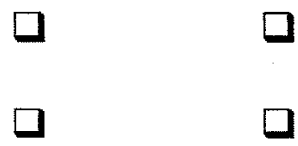

口
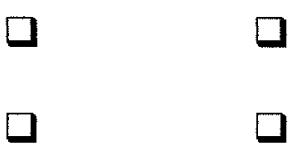

口
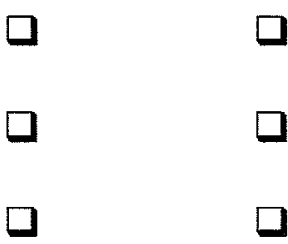

口

Comments: 
Progress Information

Date

Blood Pressure

Medications

Lipid Values

$\mathrm{Hg} \mathrm{A} \mathrm{A}_{1}$

Spot

Fasting

Comments:

Progress Information

Date

Blood Pressure

Medications

Lipid Values

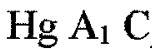

Spot

Fasting

Comments:

Progress Information

Date

Blood Pressure

Medications

Lipid Values

$\mathrm{Hg} \mathrm{A}_{1} \mathrm{C}$

Spot

Fasting

Comments: 


\section{APPENDIX B}

Diabetes Morning Program Debriefing Notes and Problem Management (2 pages)

\begin{tabular}{|l|l|l|l|}
\hline Date & Location & \# Participants & \# Guests \\
\hline & & & \\
\hline
\end{tabular}

Staff Present:

Volunteers Present:

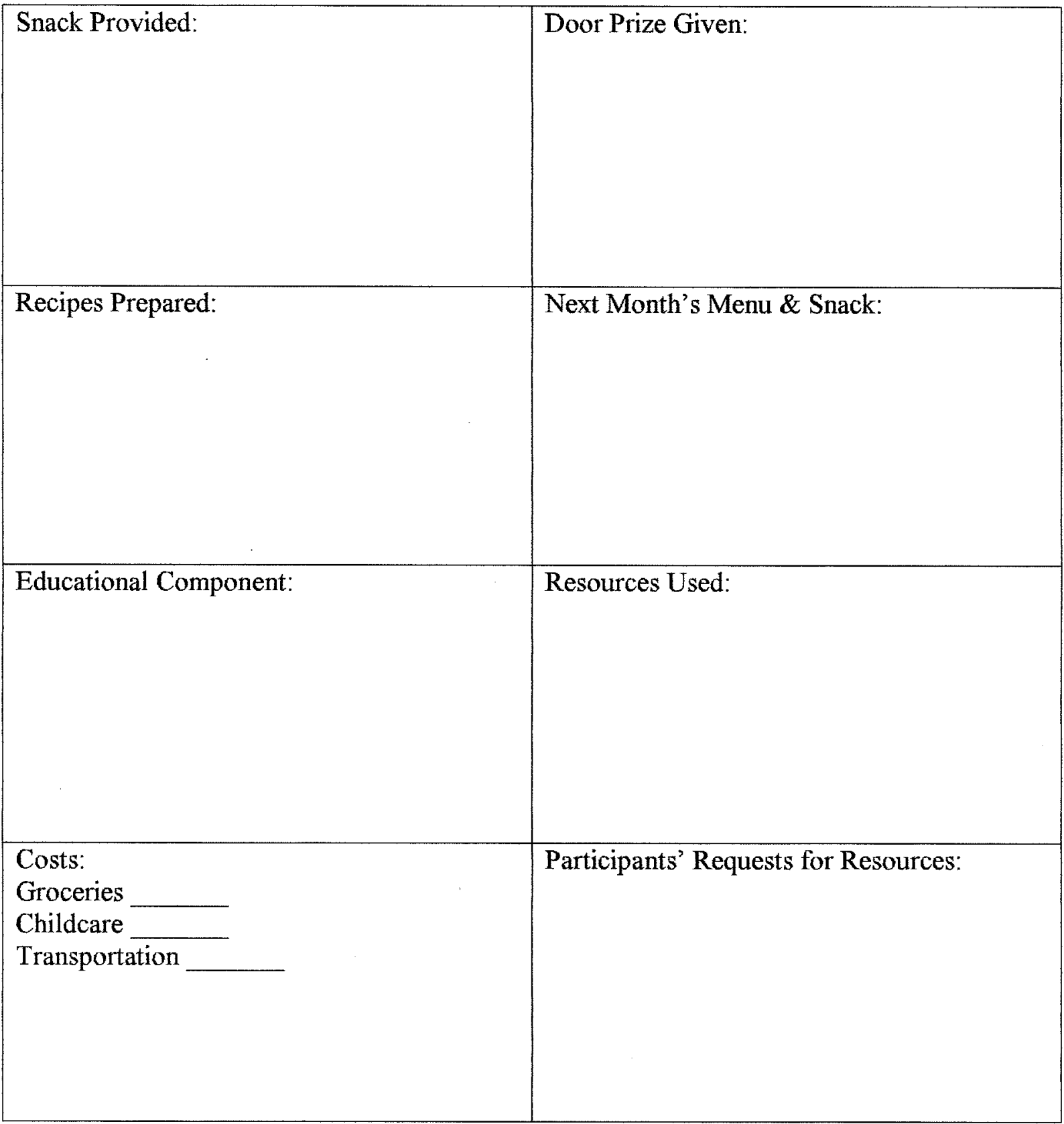




\section{Problem Management}

Describe any problems reported by participants in or out of group session that needed individual attention (e.g. problem with diabetes management and/or personal issues: housing, lack of food, problems with family, etc...)

1.

What was done to help or support the participants?

2.

What was done to help or support the participants?

3.

What was done to help or support the participants?

4.

What was done to help or support the participants? 


\section{APPENDIX C}

\section{Group Interview Guide}

\section{Introduction:}

- I will begin by thanking everyone for taking time to share her story.

- I will explain to them that I will be passing around a stone and the person with the stone can share her story.

- I will ask that each person respect each other's time to share and to hold their comments until their time to share.

- I will use plain language and use a patient, friendly and polite manner.

- Then I will ask them: "Could you share a little bit about yourself; where you are from, how long have you had diabetes?"

- I will ask who would like to start.

\section{Open-Ended Questions:}

- A sharing stone will be passed around so that the person with the stone has time to share without interruption, though I may need to prompt individuals when appropriate.

- I may prompt individuals if necessary: "Could you explain further?" "What is an example?" After each person has had an opportunity to respond to the question, I will ask the next question.

o "Think back to when you first started to come to Diabetes Morning. What was it like for you?"

O 'Now think about today and what it's like for you when you come to Diabetes Morning. Has anything changed? What might that be?"

- "Now, think about your health and well-being. Have they changed since you started to come to Diabetes Morning? Do you think that coming to Diabetes Morning has anything to do with this? How so?" 


\section{Conclusion:}

- I will conclude the interview by asking if there are any other comments, suggestions or questions.

- I will thank them for sharing their stories and explain the next steps in the research process (individual interviews and dissemination of results).

- I will explain that the individual interviews will give them an opportunity to expand on what was shared in the group today or things that you have not shared today.

- I will invite them to participate in the individual interview and give them my phone number so that they can contact me to book an interview.

- I will let them know that I will be pulling together their responses from the individual interview and the group interview over the summer and will present them with preliminary results in the fall of 2001 in a regular Diabetes Morning session. At that time, they will have an opportunity to add to the information or make clarifications before I write up the results and hand out the debriefing form. 


\section{APPENDIX D}

\section{Individual Interview Guide}

\section{For those who did not participate in the group interview:}

- I will explain the process to them and the questions that were asked.

- Then, I will present the participant with the themes or specific responses that could use elaboration that I gathered from the group interview.

- I will ask her what she thinks about them and if she has anything to add.

\section{For those who participated in the group interview:}

- I will start by asking them if there was anything they thought about after the interview that they would like to share.

- Then I will refer to the themes and specific responses that could use elaboration.

- I will ask her what she thinks about them and if she has anything to add.

\section{Conclusion:}

- I will conclude the interview by asking if there are any other comments, suggestions or questions.

- I will thank them for sharing their stories and explain the next steps in the research process (dissemination of results).

- I will let them know that I will be pulling together their responses from the individual interview and the group interview over the summer and will present them with preliminary results in the fall of 2001 in a regular Diabetes Morning session. At that time, they will have an opportunity to add to the information or make clarifications before I write up the results and hand out the debriefing form. 


\section{APPENDIX E}

\section{Consent Form: Group Interview}

\section{"Aboriginal Women Share Their Stories In An Outreach Diabetes Education Program."}

\section{Student:}

Mary Patricia Dressler

Community Health and Epidemiology

University of Saskatchewan [306] 966-2264
Supervisor:

Kathryn Green

Community Health and Epidemiology

University of Saskatchewan

[306] 966-7839

\section{Why are we doing this project?}

- To learn about how Diabetes Morning has impacted your health and well-being through the stories you share about your experiences with the program.

- Sharing information about your experiences in Diabetes Morning may help to enrich the program.

- Your stories can help indicate how well the program is working so that the best possible programs can be available in the future. Benefits are not guaranteed.

- I will use the information I gather from you for my Master's thesis and may also write articles on it for academic journals and presentations at meetings.

\section{What will we be doing in this project?}

- You can share your experiences with me in two ways: first, the meeting today, where I will ask you questions about Diabetes Morning and how you think it has affected your health and well-being; and second, if you would like, you can meet with me within the next few weeks for a oneon-one meeting.

- I will tape-record this meeting. It will probably last an hour and a half to two hours.

- Diabetes Morning will pay cab fare and $\$ 10$ in childcare if needed.

- Also, I would like to read your Diabetes Morning program files to find out how often you have come to the program and when you started coming.

- There are no risks involved in participating in this project. 


\section{What are your rights in this project?}

- You are free to withdraw from the project at any time. If you let me know that you have changed your mind about taking part in the project after being interviewed, I will not include your story.

- Withdrawal from the study will not affect your participation in Diabetes Morning or any services offered by West Side Clinic in any way.

- I will share with you any new information that may have a bearing on your decision to continue in the study.

- Your name will not be attached to the information in any way. Instead, a number code will be used to match up information so that you can remain anonymous to anyone who did not participate in the interview.

- Any materials such as audiotapes and transcripts will be locked away in a secure place at the University of Saskatchewan for a minimum of five years and then destroyed.

- I cannot guarantee confidentiality in this group interview. However, each participant is asked not to discuss what others have shared in the interview with anyone who did not participate in it.

- I will report preliminary results to you at a Diabetes Morning session. At this time you may make corrections to my interpretation.

- A transcript will be available for you to review and add, remove or change your comments.

- A summary of the results will be available upon request. 
If you have any questions, please contact me at [306] 966-2264, my supervisor at [306] 966-7839, or the Office of Research Services at [306] 966-4053.

How can you give me your permission to interview you?

$\mathrm{I}$, understand the content of the consent form I am signing and agree to participate in an interview for the present study. I agree not to discuss what others have said in the interview with anyone who did not participate in it. I also give Mary Patricia Dressler permission to obtain information about my attendance from Diabetes Morning files. I have received a signed copy of this consent form for my records.

Participant

Date
Student

Date 


\section{APPENDIX F}

\section{Consent Form: Individual Interview}

\section{"Aboriginal Women Share Their Stories In An Outreach Diabetes Education Program."}

\section{Student:}

Mary Patricia Dressler

Community Health and Epidemiology

University of Saskatchewan [306] 966-2264
Supervisor:

Kathryn Green

Community Health and Epidemiology

University of Saskatchewan

[306] 966-7839

\section{Why are we doing this project?}

- To learn about how Diabetes Morning has impacted your health and well-being through the stories you share about your experiences with the program.

- Sharing information about your experiences in Diabetes Morning may help to enrich the program.

- Your stories can help indicate how well the program is working so that the best possible programs can be available in the future. Benefits are not guaranteed.

- I will use the information I gather from you for my Master's thesis and may also write articles on it for academic journals and presentations at meetings.

\section{What will we be doing in this project?}

- Earlier, I met with a group of Diabetes Morning participants to talk about their experiences with the program. You may have been a part of this.

- Now, to find out more bout participants' experiences, I would like to talk one-on-one with those who are interested.

- I will ask you questions about your experiences with Diabetes Morning and ask you if you would have anything to say about the ideas discussed in the group interview.

- I will tape-record our conversation and take some notes. It will probably last 45 to 60 minutes.

- Diabetes Morning will pay cab fare and $\$ 10$ in childcare if needed. 
- Also, I would like to read your Diabetes Morning program files to find out how often you have come to the program and when you started coming.

- There are no risks involved in participating in this project.

\section{What are your rights in this project?}

- You are free to withdraw from the project at any time. If you let me know that you have changed your mind about taking part in the project after being interviewed, I will not include your story.

- Withdrawal from the study will not affect your participation in Diabetes Morning or any services offered by West Side Clinic in any way.

- I will share with you any new information that may have a bearing on your decision to continue in the study.

- Your name will not be attached to the information in any way. Instead, a number code will be used to match up information so that you can remain anonymous to anyone other than me.

- Any materials such as audiotapes and transcripts will be locked away in a secure place at the University of Saskatchewan for a minimum of five years and then destroyed.

- I will report preliminary results to you at a Diabetes Morning session. At this time you may make corrections to my interpretation.

- A transcript will be available for you to review and add, remove or change your comments.

- A summary of the results will be available upon request. 
If you have any questions, please contact me at [306] 966-2264, my supervisor at [306] 966-7839, or the Office of Research Services at [306] 966-4053.

How can you give me your permission to interview you?

I, understand the content of the consent form I am signing and agree to participate in an interview for the present study. I also give Mary Patricia Dressler permission to obtain information about my attendance from Diabetes Morning files. I have received a signed copy of this consent form for my records.

Participant

Date
Student

Date 


\section{APPENDIX G}

\section{Debriefing Form}

\section{Thank You For Sharing Your Story}

Thank you for sharing your experiences with the Diabetes Morning

program. I will listen carefully to your story and take out anything that could identify you. I will bring back what I learn from the stories to a session of Diabetes Morning in the fall of 2001 so that you can comment on what I find. I will take your comments into account as I write my report.

My understanding is that program planners will read my report and build your ideas into Diabetes Morning and other programs. Again, I thank you for sharing this gift of your experiences with me.

\section{Mary Pat Dressler}

Phone: 966-2264

Department of Community Health and Epidemiology

College of Medicine

University of Saskatchewan

107 Wiggins Road

Royal University Hospital

Saskatoon Saskatchewan

S7N 2E5 


\section{APPENDIX H}

\section{Transcript Release Form}

I, have reviewed the complete transcript of my personal interview in this study and acknowledge that the transcript accurately reflects what I said during the interview with Mary Pat Dressler. I hereby authorize the release of this transcript to Mary Pat Dressler to be used in the manner described in the consent form. I have received a copy of this transcript release form for my records.

Participant

Researcher
Date

Date 
1 
